\title{
Fundamentos y práctica internacional del derecho a la consulta previa, libre e informada a pueblos indígenas
}

Fecha de recepción: 15 de noviembre de 2012

Fecha de aceptación: 14 de mayo de 2013

Doi: dx.doi.org/10.12804/acdi7.2014.03

\section{Luz Ángela Patiño Palacios*}

Resumen: Este artículo describe y analiza las prácticas en derecho internacional sobre la consulta previa, libre e informada a pueblos indígenas. En primer lugar, expone los fundamentos en diferentes instrumentos internacionales en la materia, así como los criterios para una adecuada consulta. En segundo lugar, se realizan consideraciones sobre la diferencia entre el derecho a la consulta previa y el consentimiento vinculante de los pueblos indígenas. Por último, el artículo realiza una breve conclusión.

Palabras clave: Consulta previa, pueblos indígenas, consentimiento, derecho internacional.

\footnotetext{
* Abogada de la Universidad del Rosario (Colombia) con estudios de Posgrado en Derecho Ambiental de la misma Universidad, con doble titulación en Derecho Internacional de la Universidad de París II (Francia). Experiencia en derechos humanos y derecho ambiental, así como en litigio en diferentes instancias del sistema interamericano de Derechos Humanos. Correo electrónico: luzangelapatino@gmail.com

Para citar este artículo: Patiño Palacios, Luz Ángela (2014), "Fundamentos y práctica internacional del derecho a la consulta previa, libre e informada a pueblos indígenas". ACDI - Anuario Colombiano de Derecho Internacional vol. 7, pp. 69-111. doi: dx.doi.org/10.12804/acdi7.2014.03
} 
Fundamentals and the International Practice of Law Regarding Preliminary, Free and Informed Consultation by Indigenous Peoples

Abstract: This article describes and analyzes the practices in the right to free, prior, and informed consultation (FPIC) of indigenous peoples. In the first place, it presents the foundations in different international instruments in this matter, as well as the criteria for an adequate consultation. Secondly, it considers the right to prior consultation and its differences with the binding consent of indigenous peoples. Finally, the article makes a brief conclusion.

Key words: Prior Consultation, Indigenous Peoples, Consent, International Law.

Fundamentos e prática internacional do direito à consulta prévia, livre e informada a povos indígenas

Resumo: Este artigo descreve e analisa as práticas em direito internacional sobre a consulta prévia, livre e informada a povos indígenas. No primeiro lugar, expõe os fundamentos em diferentes instrumentos internacionais na matéria, assim como os critérios para uma adequada consulta. Em segundo lugar, realizam-se considerações sobre a diferença entre o direito à consulta prévia e o consentimento vinculante dos povos indígenas. Por último, o artigo realiza uma breve conclusão.

Palavras-chave: Consulta prévia, povos indígenas, consentimento, direito internacional.

\section{Introducción}

En todo el mundo existen aproximadamente 370 millones de personas indígenas que ocupan el $20 \%$ de la superficie terrestre, ${ }^{1}$ los cuales tienen grandes desafíos para sobrevivir culturalmente debido al crecimiento de la

1 Naciones Unidas, "State of the World's Indigenous Peoples", Notas descriptivas (Enero de 2010), consultado el 31 de enero de 2013, disponible en http://www.un.org/esa/socdev/ unpfii/documents/SOWIP_fact_sheets_ES.pdf 
población, la consecuente explotación de recursos naturales al interior de su territorio, su continua discriminación desde la Colonia, la subvaloración de su cultura, por un lado, y el intento de imposición de la cultura occidental como única opción de desarrollo, por otro lado. De ahí la importancia de respetar a, y dialogar con los pueblos indígenas en relación con las medidas que los afectan para preservar su diversidad étnica y cultural.

La consulta previa se ha convertido entonces en una garantía de pervivencia en un contexto de riesgo de exterminio físico y cultural, ${ }^{2}$ ya que su nacimiento se dio como una respuesta para empoderar a los pueblos indígenas luego de todas las violaciones de sus derechos cometidas en su contra. Además, la consulta se convierte en un mecanismo para hacer efectivos sus derechos, siendo un reto en la actualidad para que sea realizada y cumplida de forma adecuada y no se convierta en un mero trámite administrativo, o reunión, sino "un verdadero instrumento de participación”. ${ }^{3}$ En este sentido el presente artículo desarrollará los diferentes matices sobre el derecho a la consulta previa, libre e informada a los pueblos indígenas junto con reflexiones en torno al consentimiento.

El derecho-deber ${ }^{4}$ de consulta genera conflictos desde su concepción, ya que, por una parte, los pueblos indígenas, consideran la consulta previa como aquella facultad que tienen para tomar decisiones sobre todos los asuntos que les afecten, incluidas las actividades extractivas en sus tierras y territorios; ${ }^{5}$ en cambio, visto desde los órganos del poder

2 Organización Nacional Indígena de Colombia (ONIC), El derecho fundamental a la consulta previa de los pueblos indigenas en Colombia, Antropos, Bogotá, 2011, p. 17.

3 Corte IDH, Caso Pueblo Indígena Kichwa de Sarayaku vs. Ecuador. Fondo y reparaciones, Sentencia de 27 de junio de 2012, Serie C n. ${ }^{\circ} 245$. párr. 186.

4 En este sentido cabe resaltar que en materia de consulta previa el enfoque de derechos humanos significa que el Estado debe regular y reconocer el marco internacional de derechos humanos de forma diferencial para pueblos indígenas y tribales dentro de su legislación interna incluyendo políticas públicas, planes y procesos que garanticen el pleno ejercicio de sus derechos. Este enfoque debe ser transversal y denota la interdependencia entre diferentes derechos humanos dependiendo de la medida a adoptar. En el caso de la consulta se encuentran diferentes derechos como la vida, la integridad personal, el derecho a la no discriminación, el derecho a la propiedad, el derecho a la cultura, entre otros. Por otro lado, es un deber al exigir obligaciones de parte del Estado de respeto, protección y garantía. Así, el artículo $6^{\circ}$ numeral $1^{\circ}$ letra a) del Convenio 169 de la Oit establece que "los gobiernos deberán $[\ldots]$ consultar a los pueblos interesados" (resaltado fuera de texto original).

5 United Nations, Department of Economic and Social Affairs, Division for Social Policy and Development, Secretariat of the Permanent Forum on Indigenous Issues, Taller técnico 
estatal ${ }^{6}$ y la empresa privada, generalmente hay una coincidencia respecto a que la consulta previa es una herramienta para el establecimiento de medidas de prevención y remediación de impactos como los socio-ambientales ${ }^{7}$ manifestado que la potestad de decidir es exclusiva del Estado. ${ }^{8}$

No obstante, el procedimiento de consulta es, ante todo, un instrumento para garantizar la participación efectiva de los pueblos indígenas de las medidas administrativas o legislativas (artículo 6 a) del Convenio 169 de la OIT) susceptibles de afectarlos ${ }^{9}$ directamente, ${ }^{10} \mathrm{y}$ algunos tribunales también han incluido medidas indirectas ${ }^{11}$ teniendo en cuenta el artículo 7 numeral $3^{\circ}$ del Convenio 169 de la OIT $^{12}$ a través de un escenario dirigido a garantizar sus derechos fundamentales. ${ }^{13}$ Se puede decir entonces que, de acuerdo al Relator de Naciones Unidas, James Anaya, en general la consulta es aplicable

de las Naciones Unidas sobre el consentimiento libre, previo e informado de los pueblos indígenas (Nueva York, 17-19 de enero de 2005), p. 3.

6 Cabe destacar que "es un principio de Derecho internacional que el Estado responde por los actos de sus agentes realizados al amparo de su carácter oficial y por las omisiones de los mismos aun si actúan fuera de los límites de su competencia o en violación del derecho interno [...] El mencionado principio se adecúa perfectamente a la naturaleza de la Convención, que se viola en toda situación en la cual el poder público sea utilizado para lesionar los derechos humanos en ella reconocidos", Corte IDH, Caso Velásquez Rodríguez vs. Honduras, Fondo, Sentencia de 29 de julio de 1998. Serie C, n. ${ }^{\circ}$ 4. párr. 170 y 171.

7 Ibíd. Citando el Reglamento de Consulta y Participación para las actividades hidrocarburíferas en Tierras Comunitarias del Ecuador.

8 Ibíd., p. 3.

9 República de Colombia, Corte Constitucional, Sentencia C-175 de 2009 de 18 de marzo de 2009.

10 República de Colombia, Corte Constitucional, Sentencia C-063 de 2010 de 4 de febrero de 2010.

11 República Argentina, Juzgado de Primera Instancia n. ${ }^{\circ} 2$ en lo Civil, Comercial, Especial de Procesos Ejecutivos, Laboral y de Minería de la II Circunscripción Judicial con asiento en la ciudad de Cutral Có., "Petrolera Piedra del Águila SA c/ Curruhuinca Victorino y otros s/ acción de amparo", febrero de 2011, Considerando III, consultado el 31 de enero de 2013, disponible en: http://www.mapuexpress.net/?act=publications\&id=4766; CEACR, Observaciones individuales sobre el Convenio 169 de la OIT a Guatemala, Conferencia Internacional del Trabajo, $97^{a}$ reunión, 2008. p. 757; República de Colombia, Corte Constitucional. Sentencia T-693 de 2011 del 23 de septiembre de 2011.

12 República de Colombia, Corte Constitucional, Sentencia T-693 de 2011 del 23 de septiembre de 2011.

13 República de Colombia, Corte Constitucional, Sentencia C-175 de 2009 de 18 de marzo de 2009. 
siempre que una decisión del Estado pueda afectar a los pueblos indígenas en modos no percibidos por otros individuos de la sociedad. ${ }^{14}$

En este sentido el presente artículo pretende reflexionar sobre el contenido y alcance del derecho a la consulta previa, libre e informada a través de una metodología cualitativa principalmente desde una perspectiva del estudio de la jurisprudencia e instrumentos internacionales en la materia. Con este propósito, en primera medida el artículo desarrollará los diferentes instrumentos internacionales en los cuales se ha establecido el derecho a la consulta previa a los pueblos indígenas y algunos criterios internacionales e internos de otros Estados que se han adoptado para implementar el mismo. En segundo lugar, el artículo intenta aclarar las diferencias y exponer el alcance en relación al derecho a la consulta y el consentimiento. Por último, se expondrá una breve conclusión.

\section{Establecimiento en el derecho internacional del derecho a la consulta previa, libre e informada}

\subsection{Instrumentos internacionales}

Si bien mucho se ha dicho acerca del derecho de consulta previa, libre e informada, poco se sabe acerca de la diversidad de instrumentos internacionales que han hecho referencia a este derecho y el consentimiento de los pueblos indígenas de forma explícita. Con este propósito describiré cronológicamente algunos instrumentos y haré referencia a los criterios que se deben tener en cuenta en su implementación.

En primer lugar, respecto de los instrumentos internacionales cabe destacar que el primer tratado fue el Convenio 107 de 1957 de la Organización Internacional del Trabajo (en adelante OIT) sobre poblaciones indígenas y tribales, ${ }^{15}$ el cual fue ratificado por 27 países. ${ }^{16}$ No obstante, tiene

14 Naciones Unidas, Asamblea General. A/HrC/12/34 de 15 de julio de 2009, Consejo de Derechos Humanos, $12^{\circ}$ período de sesiones, Tema 3 de la agenda, "Promoción y protección de todos los derechos humanos, civiles, políticos, económicos, sociales y culturales, incluido el derecho al desarrollo, Informe del Relator Especial sobre la situación de los derechos humanos y las libertades fundamentales de los indígenas", James Anaya. párr. 43.

15 Llama la atención el uso de poblaciones en vez de pueblos, este último implica el reconocimiento de derechos y el carácter diferenciado y colectivo en su tratamiento.

16 OIT. Sobre el Convenio n. ${ }^{\circ} 107$ de la OIT. consultado el 31 de enero de 2012, disponible en: http://www.ilo.org/indigenous/Conventions/no107/lang--es/index.htm 
un enfoque integracionista que refleja el discurso sobre el desarrollo en el momento de su adopción. ${ }^{17}$ Durante la década de 1970, cuando la ONU comenzó a examinar la situación de los pueblos indígenas y tribales con más detalle, y cuando los pueblos indígenas comenzaron a hacerse más visibles a nivel internacional, se expidió el Convenio n. ${ }^{\circ}$ 107, el cual fue objeto de cuestionamientos ${ }^{18}$ como, por ejemplo, por usos de lenguaje discriminatorios caracterizando a los indígenas por "condiciones sociales y económicas [que] correspondan a una etapa menos avanzada". ${ }^{19}$

En consecuencia, el Consejo de Administración de la OIT convocó a una Comisión de Expertos en 1986 y esta concluyó que el "enfoque integracionista del Convenio 107 estaba obsoleto y que su aplicación era prejudicial en el mundo moderno". ${ }^{20}$ Luego, el Convenio fue revisado durante 1988-1989, y en este último año mencionado se adoptó el Convenio n. ${ }^{\circ}$ 169. ${ }^{21}$ Desde la adopción de este último tratado, ${ }^{22}$ el Convenio n..$^{\circ} 107$ ya no quedó abierto para ratificación. ${ }^{23}$ Sin embargo, continúa estando en vigencia para 17 Estados $^{24}$ respecto de 183 Estados miembros en la actualidad ${ }^{25}$ muchos de los cuales tienen poblaciones significativas de pueblos indígenas. ${ }^{26}$ No obstante, cabe destacar en relación a la consulta que el artículo 5 c) del

17 Ibíd.

18 Ibíd.

19 Artículo $1^{\circ}$ numeral 1 letra a) del Convenio 107 de la OIT.

20 Оiт. Sobre el Convenio n. ${ }^{\circ} 107$ de la OIT, consultado el 31 de enero de 2012, disponible en: http://www.ilo.org/indigenous/Conventions/no107/lang--es/index.htm

21 Ibíd.

22 Cabe destacar que el artículo $2^{\circ}$ letra a) de la Convención de Viena sobre derechos de los tratados de 1969 establece que no importará la denominación particular para ser tratados internacionales, es decir corresponden a esta categoría por ejemplo los Convenios, o Protocolos, los cuales son de carácter vinculante u obligatorio.

23 OIT. Sobre el Convenio n. ${ }^{\circ} 107$ de la OIT. Consultado el 31 de enero de 2012, disponible en: http://www.ilo.org/indigenous/Conventions/no10 7/lang--es/index.htm . El artículo 36 del Convenio 107 de la OIT establece que la ratificación de un nuevo Convenio en la materia implica una denuncia ipsojure como sucedió con los Estados que ratificaron el Convenio 169 de la OIT.

24 OIT, Ratificaciones y denuncias del Convenio n. ${ }^{\circ} 107$ de la OIT, Consultado el 31 de enero de 2012, disponible en: http://www.ilo.org/ilolex/cgi-lex/ratifcs.pl?C107

25 OIT, Estados miembros, Consultado el 31 de enero de 2012, disponible en: http:/ /www. ilo.org/public/english/standards/relm/country.htm

26 OIT, Sobre el Convenio n. ${ }^{\circ} 107$ de la OIT, Consultado el 31 de enero de 2012, disponible en: http://www.ilo.org/indigenous/Conventions/no107/lang--es/index.htm 
Convenio 107 solo estableció que se debía estimular la participación en instituciones electivas y no hizo alusión al derecho-deber de consulta, pero síal consentimiento en el artículo 4 b), al cual posteriormente se hará referencia.

El segundo instrumento adoptado sobre pueblos étnicos fue el Manual de Operaciones 2.34, conocido como "OMs 2.34" sobre pueblos tribales en el año 1982 del Banco Mundial. Este Manual fue elaborado completamente por el personal del Banco sin participación de los pueblos indígenas, ${ }^{27}$ fue muy amplio respecto de su definición de pueblos tribales incluyó características como la distinción étnica y lingüística entre la sociedad nacional; ${ }^{28}$ además, determinó que el diseño de los proyectos del Banco debían incluir medidas o componentes necesarios para salvaguardar sus intereses. ${ }^{29}$ Por consiguiente, para realizar un proyecto con el Banco en territorio de un pueblo tribal solo se necesitaba acreditar salvaguardas, y en casos en los que existieran consecuencias adversas el proyecto debía prever efectos de mitigación, ${ }^{30}$ hecho que va en contra de los actuales estándares en la materia.

Además, la oms 2.34 determinó que la información del componente tribal se aseguraba "con la participación de los afectados", es decir, el pueblo tribal, pero no con un mecanismo de consulta directo con los pueblos indígenas sino por medio de información de agencias del gobierno, estudios de prefactibilidad o antropológicos y visitas, incluyendo procedimientos consultivos para mantener la integridad cultural, así como el establecimiento de un foro ${ }^{31}$ como un programa paralelo al proyecto para la participación de los pueblos tribales en las decisiones que los afectan y la adjudicación y la reparación de agravios. ${ }^{32}$ Este Manual 2.34 no garantizaba una participación

27 Stefania Errico, "The World Bank and Indigenous Peoples: the Operational Policy on Indigenous Peoples (O.P. 4.10). Between Indigenous Peoples' Rights to Traditional lands and to Free, Prior and Informed Consent", International Journal on Minority and Group Rights 13: 367-390, 2006. 367, p. 368.

28 "Annex 1. Operational Manual Statement 2.34: Tribal People in Bank-Financed Projects (February 1982)", adjunto al documento del World Bank OPCS Working Paper Implementation of the World Bank's Indigenous Peoples Policy. A Learning Review (FY 2006-2008, agosto 2011, párr. 2 d) y f).

29 Ibíd., párr. 4.

30 Ibíd. Véase párr. 5.

31 Conforme al Diccionario de la Real Academia Española, foro es definido como una "3. $\mathrm{m}$. Reunión para discutir asuntos de interés actual ante un auditorio que a veces interviene en la discusión".

32 "Annex 1. Operational Manual Statement 2.34: Tribal People in Bank-Financed Projects (February 1982)...”, op. cit., párr. 7 y 11. 
efectiva del pueblo indígena afectado limitándose entonces a un foro que implicaba una simple reunión, no una consulta, donde los pueblos indígenas no podían determinar un alcance real de un proyecto que frecuentemente lleva años de estudios para su realización. Cabe destacar que estas disposiciones no son de carácter vinculante para los Estados por corresponder a derecho blando o soft law, sin embargo, fueron aplicadas para financiar proyectos dentro de la misma organización ocasionando la falta de garantía de los derechos de los pueblos indígenas.

Posteriormente, en el año 1989 se expidió el Convenio 169 de la OIT, el primer tratado internacional y el más importante que establece directamente el derecho a la consulta de las medidas administrativas y legislativas que los afecten de forma vinculante para los Estados (especialmente los artículos $6,7,8,12$ y 15). Sin embargo, fue limitada la participación indígena por la composición tripartita de la OIT (Estado-empleadores-trabajadores). En este sentido, el Comité de la OIT consideró que el requisito de la consulta previa debe ser visto a la luz de uno de los principios fundamentales del Convenio, tal como se expresa en el artículo 7, párrafos 1 y $3^{33}$ sobre el derecho a decidir sus propias prioridades en lo que atañe al proceso de desarrollo y se realicen estudios en este sentido.

Asimismo, debe tenerse en cuenta al momento de interpretar el Convenio 169 de la OIT el principio pro-indigena, que debe aplicarse integralmente haciendo prevalecer "los derechos y las ventajas garantizados a los pueblos interesados en virtud de otros convenios y recomendaciones, instrumentos internacionales, tratados o leyes, laudos, costumbres o acuerdos nacionales", disposición de similar naturaleza al artículo 29 de la Convención Americana de DDHH relativo al principio propersonae. ${ }^{34}$

Por otro lado, el Banco Mundial en el año 1991 aprobó la Directriz OD 4.20, la cual determinó que los "pueblos indígenas", las "minorías étnicas indígenas", los "grupos tribales" y las "tribus regulares" se agruparían en

33 "Report of the Committee Set Up to Examine the Representation Alleging Non-Observance by Colombia of the Indigenous and Tribal Peoples Convention 1989 (n. ${ }^{\circ}$ 169), Made Under Article 24 of the ILO Constitution by the Central Unitary Workers' Union (CUT) and the Colombian Medical Trade Union Association (ILO)", Doc. GB.282/14/3 (Nov. 14, 2001). párr. 59.

34 Véase Ruiz Molleda, Juan Carlos, "La implementación del derecho a la consulta previa de los pueblos indígenas", Instituto de Defensa Legal, p. 183, Lima, 2009; Yrigoyen Fajardo, R., "De la tutela indígena a la libre determinación del desarrollo, la participación, la consulta y el consentimiento", p. 17, consultado el 28 de abril de 2013, disponible en: http://ilsa.org.co:81/biblioteca/dwnlds/od/elotrdr040/od40-raquel.pdf 
la directriz como "pueblos indígenas", e incluyó la propia identificación como una de sus características. ${ }^{35} \mathrm{~A}$ su vez, consideró el debate en torno a cómo debe ser el enfoque de los pueblos indígenas, quiénes se afectan por proyectos de desarrollo, ${ }^{36}$ e incluyó dentro de los contenidos de los proyectos un marco legal del tratamiento de los derechos de los pueblos indígenas dentro del Estado. ${ }^{37}$

La estrategia de participación del Banco en la OD 4.20 es nombrada como "participación informada", la cual debía identificar experiencias locales a través de la consulta directa, incorporación del conocimiento indígena en los enfoques de proyecto y el uso adecuado y temprano de especialistas experimentados para cualquier proyecto que afecte a los pueblos indígenas y sus derechos a los recursos naturales y económicos, ${ }^{38}$ y señala que la participación debe ser a través del proyecto, la implementación y la evaluación. ${ }^{39}$ Sin embargo, el proceso de consulta mencionado no tuvo en cuenta los criterios de garantía efectiva de los derechos humanos de los pueblos indígenas entre los que se destaca que no era de forma previa y no tenían incidencia las consideraciones del pueblo implicado.

Luego, desde 1997, se aprobó el Proyecto de Declaración Americana sobre los derechos de los pueblos indígenas, el cual a la fecha no ha tenido como resultado instrumentos interamericanos.

Posteriormente, el Informe de la Comisión Mundial de Represas en el año 2000 estableció que, cuando los proyectos afecten pueblos indígenas y tribales, esos procesos deben estar guiados por el consentimiento previo, libre e informado. ${ }^{40}$ En este sentido, la CIDH otorgó medidas cautelares por la construcción de la represa Belo Monte, ${ }^{41}$ la cual fue objeto de múltiples cuestionamientos de parte de algunos Estados.

Ya en el año 2002 la Comunidad Andina de Naciones (CAN) estableció el derecho de los pueblos indígenas "a ser consultados [específicamente] en

35 “Annex 2. Operational Directive 4.20, Indigenous peoples (1991)...", op. cit., párr. 3 y 5 (b).

36 Ibíd., párr. 7.

37 Ibíd., párr. 15 (a).

38 Ibíd., párr. 8.

39 Ibíd., párr. 15 (d).

40 World Commission on Dams, Dams and Development, "Report of the World Commission on Dams", noviembre 2000, p. 34.

41 CIDH, Medida Cautelar. MC 382/10, Comunidades Indígenas de la Cuenca del Río Xingú, Pará, Brasil (otorgada el 1 de abril de 2011). 
las decisiones que se tomen sobre la explotación de los recursos naturales no renovables que se hallan en sus tierras o territorios, y sobre toda actividad que afecte al medio ambiente y sus formas de vida, [...] [y] a ser consultados y participar en la formulación, aplicación y evaluación de los planes de desarrollo que les concierna; a formular sus propios planes de desarrollo sostenible y gestionar de los Estados los recursos para su financiamiento y la cooperación internacional". ${ }^{42}$

Además, una iniciativa positiva es el compromiso que asumieron los Estados miembros de la CAN a adoptar la Declaración Internacional de los Derechos de los Pueblos Indígenas que se encontraba en preparación en el marco de las Naciones Unidas y de la Declaración Interamericana sobre los Derechos de los Pueblos Indígenas, que aún se encuentra en proceso de elaboración en la OEA. ${ }^{43}$

Luego, en el año 2005, el Banco Mundial estableció la Política Operacional OP 4.10 y las Normas de Procedimiento del Banco BP 4.10, las cuales reemplazan la Directriz Operacional OD 4.20. La OP 4.10 avanza al exigir que en todos los proyectos propuestos para financiamiento por el Banco que afectan a pueblos indígenas el prestatario (es decir, el Estado) lleve a cabo un proceso de consulta previa, libre e informada en los proyectos, así como medidas para evitar efectos adversos y reciban beneficios sociales y económicos ${ }^{44} \mathrm{el}$ cual debe ser cumplido. Este instrumento hace reflexionar sobre la falta o vacío de regulación sobre la consulta previa, libre e informada junto con su procedimiento por medio de una fuente de derecho internacional de carácter obligatorio entre Estados que refleje las relaciones entre pueblos indígenas-Estado-organizaciones internacionales.

El proceso de consulta previa, libre e informada con las comunidades indígenas afectadas de acuerdo a la O.P 4.10 se debe realizar en cada etapa del proyecto, y particularmente durante la preparación del mismo, con el objeto de conocer claramente sus opiniones y determinar si existe amplio apoyo al proyecto por parte de las comunidades indígenas. ${ }^{45}$ Además, el Banco debe

42 CAN, Carta Andina para la Promoción y Protección de los Derechos Humanos artículo 39, firmada en Guayaquil, a los veintiséis días del mes de julio del año dos mil dos, consultado el 31 de enero de 2013, disponible en: http:/ /www.comunidadandina.org/documentos/ actas/cart_DDHH.htm.

43 Ibíd., artículo 40.

44 Banco Mundial, "Políticas Operaciones OP 4.10", Manual de Operaciones del Banco Mundial, 2005, párr. 1.

45 Ibíd., párr. 7 
tener en cuenta la existencia de un apego colectivo a dicha zona, ${ }^{46}$ y en el estudio preliminar el Banco consulta también con los pueblos indígenas afectados y con el prestatario. ${ }^{47}$ Se consulta no solo con las comunidades indígenas afectadas sino con las organizaciones de pueblos indígenas, si las hubiera, ${ }^{48}$ algo que se destaca por la posibilidad de una mayor legitimidad de la adopción de la medida. Igualmente, el Banco requiere que el prestatario estudie otros posibles diseños del proyecto que permitan evitar el desplazamiento físico de pueblos indígenas pero cuando, en circunstancias excepcionales, no sea posible evitar el desplazamiento, el prestatario se abstendrá de llevarlo a cabo hasta obtener "amplio apoyo al mismo por parte de las comunidades indígenas afectadas, en el contexto del proceso de consulta previa, libre e informada" entre otras medidas. ${ }^{49}$

Por otra parte, el Banco Interamericano de Desarrollo (BID) adoptó una política operativa para pueblos indígenas en el año 2006 la cual tiene como fin cumplir con los compromisos adoptados en los ámbitos nacional e internacional sobre la consulta y participación de los pueblos indígenas en temas, actividades y decisiones que los afecten. ${ }^{50}$ Dichos mecanismos y procesos deberán tomar en cuenta el principio general del consentimiento libre, previo e informado de los pueblos indígenas como instrumento del ejercicio de sus derechos de "decidir sus propias prioridades en lo que atañe al proceso de desarrollo, en la medida que este afecte a sus vidas, creencias, instituciones y bienestar espiritual y las tierras que ocupan o utilizan de alguna manera, y de controlar, en la medida de lo posible, su propio desarrollo económico social y cultural". Por otra parte "Requerirá diagnósticos, revisiones por expertos y, siempre que sea posible, procesos de consulta y negociación de buena fe tempranos y socioculturalmente apropiados encaminados a identificar los afectados indígenas y sus representantes genuinos, y a identificar y evaluar los beneficios e impactos potenciales sobre los pueblos o grupos indígenas". ${ }^{51}$

Finalmente, en el año 2007, la Organización de Naciones Unidas (ONU) adoptó la Declaración de las Naciones Unidas sobre los derechos

46 Ibíd., párr. 4 y 6.

47 Ibíd., párr. 8.

48 Ibíd., párr. 8 y 10.

49 Ibíd., párr. 8.

50 Banco Interamericano de Desarrollo, "Política operativa sobre pueblos indígenas y estrategia para el desarrollo indígena”, julio, 2006, p. 38.

51 Ibíd., p. 47. 
de los pueblos indígenas, instrumento de suma importancia en el ámbito universal por ser progresista y un desarrollo sustancial de los derechos de dichos pueblos, contando con la participación de los pueblos indígenas. Adicionalmente establece que deben consultarse las medidas eficaces para combatir los prejuicios y eliminar la discriminación y promover la tolerancia, la comprensión y las buenas relaciones entre los pueblos indígenas y todos los demás sectores de la sociedad (artículo 15, n. ${ }^{\circ}$ ), las medidas específicas para proteger a los niños indígenas contra la explotación económica y contra todo trabajo que pueda resultar peligroso o interferir en la educación del niño, o que pueda ser perjudicial para la salud o el desarrollo físico, mental, espiritual, moral o social del niño (artículo 17, n. $^{\circ}$ 2), antes de utilizar sus tierras o territorios para actividades militares (artículo $30 \mathrm{n} .{ }^{\circ}$ 2) como, por ejemplo, usando explosivos para perforaciones, o por conflicto armado, ${ }^{52}$ las medidas que el Estado adopte sobre pueblos indígenas transfronterizos (artículo 36) y las medidas apropiadas, incluidas medidas legislativas, para alcanzar los fines de la declaración mencionada (artículo 38). Además, cabe resaltar que esta declaración fue aprobada por la Asamblea General, la cual goza de una alta representatividad y legitimidad al estar compuesta a la fecha por 193 Estados miembros.

Al lado de ello, el Relator de Naciones Unidas sobre los derechos de los pueblos indígenas consideró que el derecho-deber de consultar a los pueblos indígenas ha sido aceptado de modo general por los Estados en sus contribuciones a las discusiones en los borradores de las declaraciones sobre pueblos indígenas tanto en Naciones Unidas ${ }^{53}$ como en el sistema interame-

52 Véase Comisión Interamericana de Derechos Humanos. Comunidad San Vicente Los Cimientos vs. Guatemala, Caso 11.197. Informe n. ${ }^{\circ}$ 68/03 (solución amistosa) (10 de Octubre de 2003).

53 Cabe destacar que en la aprobación de la Declaración de Naciones Unidas sobre los derechos de los pueblos indígenas aprobada por la Asamblea General el 13 de septiembre de 2007 (A/RES/61/295) el Estado de Colombia se abstuvo de votar, sin embargo, "En abril de 2009, el Gobierno Nacional envió una comunicación al Secretario General de Naciones Unidas expresando el respaldo unilateral de Colombia a la Declaración", en Colombia y el Examen Periódico Universal de Derechos Humanos (EPU) ante el Consejo de Derechos Humanos de las Naciones Unidas: Experiencias, avances y desafíos, p. 28. consultada el 29 de abril de 2013, disponible en: http:/ /lib.ohchr.org/HRBodies/UPR/Documents/Session3/CO/Colombia_UPR. pdf). Véase Gómez Rojas, José Fernando. "Argument Analysis of the Position of Colombia regarding the UN Declaration on the Rights of Indigenous Peoples, 16 International Law", Revista Colombiana de Derecho Internacional, 143-176 (2010), consultada el 29 de abril de 2013, disponible en: http://www.scielo.org.co/pdf/ilrdi/n16/n16a06.pdf, y ONU, "Foro Permanente para cuestiones indígenas. Declaración de Naciones Unidas sobre los derechos de los 
ricano, siendo ampliamente aceptada, con lo que se demuestra que la norma de consulta se ha convertido en parte del derecho internacional consuetudinario. ${ }^{54}$ A su vez, la Corte Interamericana de Derechos Humanos (Corte IDH) estableció que la obligación de consulta, además de constituir una norma convencional, es también un principio general del derecho internacional. ${ }^{55}$

Por consiguiente, en la actualidad existe un derecho de consultar y su omisión genera responsabilidad internacional, como sucedió, por ejemplo, en el caso Sarayaku. ${ }^{56}$ Por otro lado, en el caso del sistema interamericano de

pueblos indígenas", consultada el 29 de abril de 2013, disponible en: http://social.un.org/ index/indigenouses/Portada/Declaraci $\%$ C3\%B3n.aspx. En este sentido, cabe resaltar que la costumbre no es aplicable en casos de objetores persistentes, es decir oponiéndose frente a cualquier intento de aplicar la regla de derecho, véase IcJ, Fisheries case (United Kingdom v. Norway, Judgment of December 18 ${ }^{\text {th }}, 1951$, p. 131. Además, "una resolución de la AG puede ser la expresión o contribuir a la formación de una norma consuetudinaria y, al mismo tiempo, constituir la prueba del Estado de cualquiera de sus elementos constitutivos", p. 549. Remiro Brontóns, A. y otros, Derecho internacional. Valencia, 2007.

54 Anaya, J., 'Indigenous peoples' participatory rights in relation to Decisions about natural resource extraction: the more fundamental issue of what rights indigenous peoples have in lands and resources", Arizona Journal of International \& Comparative Law, Vol 22, n. ${ }^{\circ}$ 1., p. 7. Sin embargo, no especificó qué tipo de costumbre es (universal, regional, local).

55 Corte IDH, Caso Pueblo Indígena Kichwa de Sarayaku vs. Ecuador. Fondo y reparaciones, Sentencia de 27 de junio de 2012, Serie C n. ${ }^{\circ} 245$. párr. 164. Si bien la Corte Interamericana de DDHH no profundiza en este sentido, cabe destacar que no hace referencia a "los principios generales de derecho" que trata el artículo 38 del Estatuto de la Corte Internacional de Justicia como fuente de derecho internacional sino a un "principio general de derecho internacional". De acuerdo a la doctrina estos últimos principios "o bien el término se refiere a las reglas fundamentales que, sin ser ellas-mismas directamente operativas, generan normas más precisas —así como la buena fe [...] o bien el reenvío a estas reglas, deducidas de esos principios iniciales, aparecen como una consecuencia necesaria, se encuentran contenidos implícitamente, de manera que solo abstrayéndolos actualizan su existencia latente- así la CIJ en el caso de la Delimitación de la plataforma continental en Mar del Norte, deduciendo el recurso obligatorio a los 'principios de equidad' de 'preceptos muy generales de la justicia y la buena fe' (...) estos principios entonces no tienen solamente una existencia positiva, sino que se interponen entre otras reglas como un elemento de razonamiento jurídico. O bien el término se refiere al carácter fragmentado de las normas involucradas, incluyendo el contenido abstracto y de aplicación general para ser desarrollado — así como el principio del derecho de los pueblos a la autodeterminación o el de la soberanía permanente sobre los recursos naturales- Reglas parciales en vía de formación, en cuanto a su contenido, sino también en cuanto a su autoridad legal", Combacau, J. y Sur, S., Droit international public, Montchrestien, París, 2006, p. 110 (traducción no oficial).

56 Corte IDH, Caso Pueblo Indígena Kichwa de Sarayaku, Ecuador, Fondo y reparaciones, Sentencia de 27 de junio de 2012, Serie C n. ${ }^{\circ}$ 245, párr. 164. 
derechos humanos existe una obligación de parte de los Estados de adopción de medidas en derecho interno para poder ser efectivos los derechos establecidos a nivel convencional (artículo 2 de la Convención Americana sobre Derechos Humanos — CADH—), y en este sentido se debe realizar un control de convencionalidad sobre las medidas ${ }^{57}$ implementadas en materia de consulta. Además, existe una obligación positiva del Estado (artículo 1.1 de la CADH) de garantizar y prevenir afectaciones contra la identidad cultural de los pueblos indígenas de carácter reforzado por tratarse de sujetos que requieren especial atención. Por lo tanto, los estándares internacionales son muy amplios y fragmentados en diferentes instrumentos internacionales. No obstante, la interpretación debe ser evolutiva, ${ }^{58}$ es decir conforme a las condiciones actuales para garantizar la plena efectividad de derechos.

\subsection{Criterios para la realización adecuada de una consulta}

El derecho a la consulta es un corolario de un gran número de derechos humanos aceptados universalmente, entre ellos el derecho a la adopción de medidas internas, la integridad cultural, el derecho a la no discriminación y el derecho a la propiedad, y los derechos conexos como se indica en las declaraciones y decisiones del Comité de Derechos Humanos, el Comité para la Eliminación de la Discriminación Racial y la Corte IDH, respectivamente. ${ }^{59}$ Sin lugar a duda, el derecho a la consulta previa es considerado como un derecho humano, o derecho fundamental, y en consecuencia goza de ser respetado y garantizado.

Además, el derecho a la consulta puede estar relacionado con el derecho a la cultura, ya que las decisiones que afecten al territorio se vinculan directamente a la obligación estatal de adoptar medidas especiales para

57 Véase Corte IDH, Caso Gelman vs. Uruguay, Fondo y Reparaciones, Sentencia de 24 de febrero de 2011, Serie C n. ${ }^{\circ}$ 221, párr. 193; Corte IDH, Caso Almonacid Arellano y otros vs. Chile, Excepciones Preliminares, Fondo, Reparaciones y Costas, Sentencia de 26 de septiembre de 2006, Serie C n. ${ }^{\circ}$ 154, párr. 124; Corte IDH, Caso Radilla Pacheco vs. México, Excepciones Preliminares, Fondo, Reparaciones y Costas, Sentencia de 23 de noviembre de 2009, Serie C n. ${ }^{\circ} 209$, párr. 339.

58 Véase Corte IDH, Caso de la Comunidad Mayagna (Sumo) Awas Tingni vs. Nicaragua, Fondo, Reparaciones y Costas, Sentencia de 31 de agosto de 2001, Serie C n. ${ }^{\circ}$ 79, párr. 148; Corte IDH. Caso de los "Niños de la Calle", Villagrán Morales y otros vs. Guatemala, Fondo, Sentencia de 19 de noviembre de 1999, Serie C n. ${ }^{\circ}$ 63, párr. 193.

59 Naciones Unidas. Asamblea General. A/HRC/12/34 de 15 de julio de 2009..., op. cit., párr. 41. 
proteger el derecho a la identidad cultural, basada en una forma de vida intrínsecamente ligada al territorio. ${ }^{60}$ De acuerdo a lo anterior, para la Corte IDH la falta de consulta a un pueblo puede afectar su identidad cultural, por cuanto no cabe duda de que la intervención y destrucción de su patrimonio cultural implican una falta grave al respeto debido a su identidad social y cultural, a sus costumbres, tradiciones, cosmovisión y a su modo de vivir. ${ }^{61}$

En primer lugar, la consulta debe ser previa, ${ }^{62}$ implicando un elemento temporal para satisfacerla, es decir esta debe realizarse desde la etapa de estudios de factibilidad o planeación y no al final, en el momento previo a la ejecución, ya que este tipo de práctica desconoce los derechos de los pueblos indígenas al romper los tiempos propios de las comunidades étnicas. ${ }^{63}$ Su fundamento se encuentra en los artículos $6^{\circ}$ numeral $1^{\circ}$ letra a) y $15^{\circ}$ del Convenio 169 de la OIT, así como el artículo 19 de la Declaración de Naciones Unidas sobre derechos de los pueblos indígenas.

Para ello, conforme a las especificidades y exigencias propias de cada caso, al momento de la consulta inicial se deberán fijar los tiempos de revisión a corto, mediano y largo plazo. ${ }^{64} \mathrm{El}$ proceso de consulta debe estar precedido de un trámite pre-consultivo en el cual se defina, de común acuerdo entre las autoridades gubernamentales y los representantes de los pueblos indígenas, las bases del procedimiento participativo ${ }^{65}$ acerca de cómo se efectuará el

$60 \mathrm{CIDH}$, Derechos de los pueblos indígenas y tribales sobre sus tierras ancestrales y recursos naturales, Normas y Jurisprudencia del Sistema Interamericano de Derechos Humanos, OEA/Ser.L/V/II, Doc. 56/09 (30 diciembre 2009), párr. 276.

61 Corte IDH, Caso Pueblo Indígena Kichwa de Sarayaku vs. Ecuador, Fondo y reparaciones, Sentencia de 27 de junio de 2012, Serie C n. ${ }^{\circ}$ 245, párr. 220.

62 Corte IDH, Caso del Pueblo Saramaka, vs. Surinam, Excepciones Preliminares, Fondo, Reparaciones y Costas, Sentencia de 28 de noviembre de 2007, Serie C n. ${ }^{\circ} 172$, párr. 194 a); $\mathrm{CIDH}$, Derechos de los pueblos indígenas y tribales sobre sus tierras ancestrales..., op. cit., párr. 275; República de Colombia, Corte Constitucional. Sentencia T-129 de 2011 (3 de marzo de 2011), p. 71.

63 República de Colombia, Corte Constitucional, Sentencia T-129 de 2011 (3 de marzo de 2011). p. 76.

64 Ibíd.

65 República del Ecuador, Corte Constitucional, Quito, 18 de marzo de 2010, Sentencia n. ${ }^{\circ}$ 001-10-SIN-CC. Casos n. ${ }^{\circ}$ 0008-09-IN y 0011-09-IN (Acumulados); República de Colombia, Corte Constitucional, Sentencias C-175 de 2009 de 18 de marzo de 2009, C-702 de 2010 de 6 de septiembre de 2010, C-461 de 2008 de 14 de mayo de 2008 y T-745 de 2010 de 14 de septiembre de 2010 . 
proceso consultivo, ${ }^{66}$ el cual deberá corresponder a la medida a consultar, y las características propias del pueblo indígena que podría ser afectado.

En esta etapa previa se sugiere realizar una evaluación exhaustiva junto con participación indígena para determinar si existen otras comunidades étnicas a quienes se requiera consultar; ${ }^{67}$ buscando una mayor eficiencia, equidad y no contradicción de los procesos de consulta se debería intentar realizar una consulta conjunta con diferentes comunidades étnicas de un mismo territorio, por ejemplo, si existiera un mismo proyecto en territorio indígena y afrodescendiente. ${ }^{68}$ Es un reto complejo pero muy fructífero que fomenta un diálogo en un espacio multicultural. Además, en todas las etapas se podría constituir una instancia de participación que incluyera terceros intervinientes que pueden coadyuvar en la garantía de los derechos de los pueblos indígenas.

En segundo lugar, la consulta debe ser libre, ${ }^{69}$ esto es, participar en todos los niveles en la formulación, implementación y evaluación de medidas y programas que los afecten, ${ }^{70}$ sin ningún tipo de intromisión o de presión sobre la comunidad que afecte el principio de libertad y por lo tanto vicie las decisiones que se tomen. ${ }^{71}$ La libertad de decisión de los pueblos indígenas también se afecta cuando se asesina o se desaparece a los líderes que se

66 República de Colombia, Corte Constitucional, Sentencia T-737 de 2005 de 14 de julio de 2005.

67 Se podría pensar en realizar un registro de pueblos indígenas con la participación e insumo de sus autoridades.

68 Se requiere reglamentar a nivel interno y/o establecer desde el inicio de las medidas consultadas con los pueblos indígenas y tribales el procedimiento a seguir en caso de estar en desacuerdo dos comunidades étnicas afectadas y que deben ser consultadas, por ejemplo, por un proyecto en un territorio de ambos.

69 Su fundamento jurídico se encuentra en el artículo 16 numeral $2^{\circ}$ del Convenio 169 de la OIT, los artículos 10,11, 19, 28 a 30 y 32 de la Declaración de Naciones Unidas sobre derechos de los pueblos indígenas, y el artículo 1.1. de la Convención Americana sobre derechos humanos.

70 Report of the Committee Set Up to Examine the Representation Alleging Non-Observance by Colombia of the Indigenous and Tribal Peoples Convention 1989 (n. ${ }^{\circ}$ 169), Made Under Article 24 of the ILO Constitution by the Central Unitary Workers' Union (CUT) and the Colombian Medical Trade Union Association, ILO, Doc. GB.282/14/3, noviembre 14, 2001., párr. 61.

71 Organización Nacional Indígena de Colombia (ONIC), El derecho fundamental a la consulta previa de los pueblos indigenas en Colombia, Antropos, Bogotá, 2011, p. 22. 
opongan a la realización de un proyecto. ${ }^{72}$ Significa entonces que la consulta debe ser libre en el sentido en que no debe existir ninguna manipulación o predeterminación que conduzca a la adopción de determinada posición, es decir, no debe haber intimidación o presión, esta última implica riesgos reales. En casos de conflicto armado no existe un consentimiento libre hasta tanto no existan las debidas garantías para su realización, en consecuencia, mientras continúe el conflicto, se pueden proponer áreas de exclusión de medidas por encontrarse viciado el procedimiento al mediar fuerza dependiendo del caso.

En tercer lugar, la consulta debe ser informada, lo cual implica que los pueblos indígenas deben disponer de tiempo suficiente para realizar su propio proceso de adopción de decisiones y participar en las decisiones tomadas en consonancia con sus prácticas culturales y sociales. ${ }^{73}$ Este deber requiere que el Estado acepte y brinde información e implica una comunicación constante entre las partes, ${ }^{74}$ brindando información al respecto en un formato entendible y públicamente accesible ${ }^{75}$ ya que el aviso temprano proporciona un tiempo para la discusión interna dentro de las comunidades y para brindar una adecuada respuesta al Estado ${ }^{76}$ (acceso a la información). Por ejemplo, tratándose de proyectos se deben conocer los alcances del proyecto a desarrollar. Con este fin se deberían realizar estudios antropológicos por parte de expertos imparciales acerca de la afectación al interior de los pueblos sobre su cosmovisión y la forma como debe desarrollarse la consulta dentro de un pueblo indígena específico, y, a su vez, traducir a la lengua del pueblo estos estudios para su comprensión.

Una interpretación sistemática de la jurisprudencia y de los instrumentos del sistema interamericano de protección de los derechos humanos permite establecer que el derecho de acceso a la información "apareja el acceso de los pueblos indígenas a que el Estado les suministre información accesible, suficiente y oportuna sobre dos aspectos: (1) la naturaleza y el impacto de la intervención externa sobre bienes o recursos de su propiedad y

72 Ibíd.

73 Naciones Unidas, Asamblea General, Consejo de Derechos Humanos, Informe definitivo del Estudio sobre los pueblos indígenas y el derecho a participar en la adopción de decisiones, 17 de agosto de 2011, p. 19.

74 Corte IDH, Caso del Pueblo Saramaka vs. Surinam, Excepciones..., op. cit., párr. 133.

75 Corte IDH, Caso del Pueblo Saramaka vs. Surinam, Interpretación de la Sentencia de Excepciones Preliminares, Fondo, Reparaciones y Costas, Sentencia de 12 de agosto de 2008, Serie C n. ${ }^{\circ} 185$ párr. 17.

76 Corte IDH, Caso del Pueblo Saramaka vs. Surinam. Excepciones..., op. cit., párr. 133. 
(2) el proceso de consulta que se va a adelantar y las razones que lo justifican.Solo de esta manera puede asegurarse que la información entregada por el Estado conducirá a que la formación de la voluntad de las comunidades en los procesos de decisión, en torno a la exploración y explotación de los recursos naturales en sus territorios, sea genuinamente libre e informada". ${ }^{77}$

Además, la información debe ser transparente, lo cual se refiere al conocimiento de las consecuencias de tales medidas, sean estas positivas o negativas. ${ }^{78}$ Es importante que también se conozcan cuáles van a ser las metodologías de la consulta, así como las normas pertinentes que sustenten la medida. ${ }^{79}$ El principio de transparencia a su vez implica que la documentación relevante tendría que ser traducida a la lengua tradicional a fin de que la comprensión de los mismos pueda garantizarse con plenitud, ${ }^{80}$ así como el acompañamiento de intérpretes en todo el diálogo.

En cuarto término, el proceso de consulta debe realizarse con procedimientos culturalmente adecuados o apropiados teniendo como fin llegar a un acuerdo, consenso u obtención de consentimiento. ${ }^{81}$ Estos procedimientos no se encuentran regulados de forma particular en el plano internacional, sin embargo, deben tener formas flexibles ${ }^{82}$ de acuerdo a sus usos y costumbres.

77 Comisión Interamericana de Derechos Humanos, "El derecho de acceso a la información en el marco jurídico interamericano", Relatoría Especial para la Libertad de Expresión, OEA/ Ser.L/V/II. CIDH/RELE/INF. 1/09, 30 de diciembre de 2009, párr. 71.

78 República del Perú, Sentencia del Tribunal Constitucional, Exp. n. ${ }^{\circ}$ 0022-2009-pi/tc, Lima..., op. cit., párr. 35.

79 Ibíd.

80 Ibíd.

81 Corte IDH, Caso del Pueblo Saramaka vs. Surinam, Excepciones..., op. cit., párr. 133; OIT, Reclamación (artículo 24), Reclamación (artículo 24), 2006, Brasil - C169, Informe del Comité encargado de examinar la reclamación en la que se alega el incumplimiento por Brasil del Convenio sobre pueblos indígenas y tribales, 1989 (n. $\left.{ }^{\circ} 169\right)$ ), presentada en virtud del artículo 24 de la Constitución de la OIT por el Sindicato de Ingenieros del Distrito Federal (SENGE/ DF).párr. 42; República de Colombia, Corte Constitucional, Sentencias: T- 129 de 2011 de 3 de marzo de 2011, p. 77, y sentencia C-175 de 2009 de 18 de marzo de 2009; República Argentina, Juzgado de Primera Instancia n. ${ }^{\circ}$ 2. en lo Civil, Comercial, Especial de Procesos Ejecutivos, Laboral y de Minería de la II Circunscripción Judicial con asiento en la ciudad de Cutral Có, "Petrolera Piedra del Águila S.A. c/ Curruhuinca Victorino y otros s/ acción de amparo", febrero de 2011; República de Bolivia, Sentencia Constitucional 2003/2010-R Sucre, 25 de octubre 2010 contra la Asamblea del Pueblo Guaraní Itika Guasu, Expediente 2008-17547-36-rac Distrito: Tarija. Magistrado Relator: Dr. Marco Antonio Baldivieso Jinés; Naciones Unidas. Asamblea General, A/HRC/12/34 de 15 de julio de 2009..., op. cit., párr. 49. 82 Artículo 34 del Convenio 169 de la OІт. Asimismo cabe destacar que el Convenio debe 
Una posibilidad es incluir tres etapas: 1) Fase de pre-consulta, 2) Fase de realización de consulta y 3) Fase de seguimiento y control, ${ }^{83}$ o en otros términos la posibilidad de intervención del pueblo indígena involucrado antes, durante y después de la medida consultada. ${ }^{84}$ En este aspecto es importante involucrar la supervisión, seguimiento, verificación y acompañamiento de parte de instituciones del Estado garantistas de los derechos humanos, a la empresa y el pueblo indígena en todo el proceso de consulta, y es deseable incluir un comité en este sentido desde la fase pre-consultiva.

También, desde la fase pre-consultiva se podrían realizar radiografías étnicas, determinar tiempos y plantear la posibilidad de etno-reparaciones a nivel colectivo y/o de forma individual en caso de realizarse una medida consultada, debido a que posteriormente se pueda fraccionar el colectivo por intereses particulares. Además, durante el proceso de consulta no se debe limitar al goce efectivo a un territorio colectivo.

Cabe resaltar que la ausencia de regulación de la consulta no exime al Estado de dicho deber, ${ }^{85}$ y en caso de omitir esta obligación se podría incurrir en responsabilidad internacional, así como decisiones internas inconstitucionales o insanablemente nulas dependiendo del Estado. ${ }^{86} \mathrm{~Pa}$ ra esto se deberían desarrollar lineamientos, directrices o procedimientos flexibles (artículo 34 del Convenio 169 de la OIT) en derecho interno, por ejemplo, a través de leyes de consulta con pautas o criterios que se adapten

ser interpretado de buena fe, de acuerdo a su sentido corriente y teniendo en cuenta su objeto y fin (artículo 31 numeral 1 de la Convención de Viena sobre derechos de los tratados de 1969). Por otra parte, se requieren formas flexibles, entendiendo por flexible conforme a lo establecido por el diccionario de la Real Academia Española, de la siguiente forma: "3. adj. Que no se sujeta a de normas estrictas, a dogmas o trabas". Consultado el 28 de abril de 2013, disponible en: http://lema.rae.es/drae/?val=FLEXIBLE

83 Rodríguez, Gloria Amparo. La consulta previa en pueblos indígenas y comunidades afrodescendientes en Colombia (2010). P. 78. Consultado el 29 de abril de 2013, disponible en: http://www.urosario.edu.co/urosario_files/1f/1fd9b49f-b717-4dc1-8875-657612776cff.pdf

84 República de Colombia, Corte Constitucional, Sentencia T-129 de 2011 de 3 de marzo de 2011.

$85 \mathrm{CIDH}$, Derechos de los pueblos indígenas y tribales sobre sus tierras ancestrales..., op. cit., párr. 298.

86 República Argentina, Juzgado de Primera Instancia n. ${ }^{\circ} 2$ en lo Civil, Comercial, Especial de Procesos Ejecutivos, Laboral y de Minería de la II Circunscripción Judicial con asiento en la ciudad de Cutral Có, "Petrolera Piedra del Águila S.A. c/ Curruhuinca Victorino y otros s/ acción de amparo", febrero de 2011, Considerando III, disponible en: http:/ /www.mapuexpress.net $/$ ?act $=$ publications\&id $=4766$ 
a cada pueblo teniendo en cuenta desarrollos jurisprudenciales compatibles con los estándares internacionales en la materia, ya que los mecanismos elaborados unilateralmente ignoran a una de las partes e implican una subordinación.

Por otro lado, la consulta debe ser efectiva ${ }^{87}$ y garantizar la participación real de las comunidades afectadas. ${ }^{88}$ Cuando la concertación no es posible, la decisión sobre el proyecto de desarrollo recae en el Estado y, si llega a estar en contra del consentimiento indígena, deberá justificar o mo$\operatorname{tivar}^{89}$ su pronunciamiento y establecer, entre otras cosas, que el proyecto la beneficia y no viola la integridad cultural. ${ }^{90}$ Otros criterios para que sea adecuada es que debe estar desprovista de autoritarismo y arbitrariedad (acto dictado exclusivamente por la voluntad del sujeto). ${ }^{91}$

Principalmente la consulta debe realizarse conforme al principio rector de buena $\mathrm{fe}^{92}$ entendido como aquel que busca evitar actitudes o conductas que pretendan la evasión de lo acordado, interferir u omitir y, por

87 Corte IDH, Caso del Pueblo Saramaka vs. Surinam Excepciones..., op. cit., párr. 194 a); OIT, Reclamación (artículo 24). 2006, Brasil, C169..., op. cit., párr. 44; Naciones Unidas. Pacto Internacional de Derechos Civiles y Políticos, CCPR/C/95/D/1457/2006 de 24 de abril de 2009, Comité de Derechos Humanos, $95^{\circ}$ período de sesiones, 16 de marzo a 3 de abril de 2009, Comunicación no 1457/2006, Presentada por: Ángela Poma Poma (representada por el abogado Tomás Alarcón), Estado Parte: Perú, párr. 7.6; The African Commission on Human and Peoples' Rights. Communication 276 / 2003, Centre for Minority Rights Development (Kenya) and Minority Rights Group International on behalf of Endorois Welfare Council v. Kenya, párr. 227 y 228; CIDH. Derechos de los pueblos indígenas y tribales sobre sus tierras ancestrales..., op. cit., párr. 275; Office of the High Commissioner for Human Rights, CERD, General Recommendation n. ${ }^{\circ}$ 23: Indigenous peoples: 18/08/1997. párr. 4(d).

88 República de Colombia, Corte Constitucional, Sentencia C-615 de 2009 (2 de septiembre de 2009).

89 Con este fin se debe realizar un análisis objetivo de proporcionalidad y razonabilidad de la medida.

90 República de Colombia, Corte Constitucional, Sentencia T-154 de 2009 (12 de marzo de 2009).

91 República de Colombia, Corte Constitucional, Sentencias: SU-039 de 1997 (3 de febrero de 1997), C-175 de 2009 (18 de marzo de 2009), y T-769 de 2009 (29 de octubre de 2009).

92 Artículo 6.2 del Convenio 169 de la OIT; Corte IDH, Caso del Pueblo Saramaka vs. Surinam, Excepciones..., op. cit., párr. 133; OIT, Reclamación (artículo 24), 2006, Brasil, C169..., op. cit., párr. 42; República de Colombia, Corte Constitucional, Sentencias: C-175 de 2009 (18 de marzo de 2009) y C-891 de 2002 (22 de octubre de 2002); Naciones Unidas, Asamblea General, A/ HRC/12/34 de 15 de julio de 2009..., op. cit., párr. 49; CIDH, Derechos de los pueblos indígenas y tribales sobre sus tierras ancestrales..., op. cit., párr. 292. 
el contrario, cooperar con el desarrollo de la otra parte, como en el cumplimiento de lo convenido ${ }^{93}$ con este fin se requiere que los funcionarios que se encuentren dentro de todo el proceso de consulta sean capacitados en la materia porque muchas veces no conocen el alcance de la misma. Un ejemplo de mala fe es la realización de la consulta de forma inoportuna ${ }^{94} \mathrm{O}$ convertir en accionistas a los pueblos indígenas como estrategia para fraccionar el pueblo y con el fin de no realizar una consulta, generando la pérdida cultural del mismo. A su vez, es reprochable la entrega de forma individual becas, regalos, viajes a líderes, comida, infraestructura o desigualdad en los beneficios de parte de la empresa durante el proceso de consulta, teniendo la posibilidad de generar división al interior del respectivo pueblo.

En consecuencia, la instauración de un clima cordial es necesario en razón a la desconfianza hacia las instituciones del Estado y el sentimiento de marginación que encuentran sus raíces en realidades históricas sumamente antiguas y complejas y que no terminan de superarse aún. ${ }^{95}$ La creación de un sistema eficaz de comunicación entre las partes interesadas ${ }^{96}$ se convierte en una herramienta útil. Además, la creación de entidades que coordinen en todos los órganos estatales, así como entidades especializadas ${ }^{97}$ sobre los mecanismos de consulta facilita el diálogo.

Por consiguiente, los Estados tienen la obligación de consultar a los pueblos indígenas y garantizar su participación en las decisiones relativas a cualquier medida que afecte sus territorios. ${ }^{98}$ En general hay que consultar la adopción de medidas legislativas, administrativas o de otra índole que

93 República del Perú, Sentencia del Tribunal Constitucional, Sentencia del Tribunal Constitucional de 9 de junio de 2010, Exp. n. ${ }^{\circ}$ 0022-2009-pi/tc, Lima..., op. cit., párr. 27.

94 República de Colombia, Corte Constitucional, Sentencia C-175 de 2009 de 18 de marzo de 2009.

95 Naciones Unidas. Asamblea General, A/ HRC/12/34 de 15 de julio de 2009..., op. cit., párr. 50.

96 Rodolfo Stavenhagen, "Los pueblos indígenas y sus derechos", Informes Temáticos del Relator Especial sobre la situación de los Derechos Humanos y las Libertades Fundamentales de los Pueblos Indígenas del Consejo de Derechos Humanos de la Organización de las Naciones Unidas (Oficina de UNESCO en México) p. 163.

97 Ministerio Público de la Defensa de Argentina, Acceso a la justicia de los pueblos indígenas, 2010, p. 111.

$98 \mathrm{CIDH}$, Derechos de los pueblos indígenas y tribales sobre sus tierras ancestrales..., op. cit., párr. 273. 
sean necesarias para reconocer y garantizar el derecho a ser efectivamente consultado, de conformidad con sus tradiciones y costumbres. ${ }^{99}$

Ahora bien, dada la dificultad en determinar todas las medidas de forma más específica que deben ser materia de consulta expondré algunos ejemplos de lo que debe ser consultado conforme a pronunciamientos internacionales e internos (estos últimos deben ser compatibles con los estándares internacionales, de lo contrario no deberán ser aplicados):

- Cualquier medida legislativa o administrativa (por ejemplo, en Colombia leyes, decretos o resoluciones proferidas por la rama ejecutiva del Estado) que regule el derecho de consulta previa en un Estado. ${ }^{100}$

- La explotación de recursos naturales ${ }^{101}$ o afectación de los territorios ancestrales por las comunidades étnicas incluyendo sus recursos naturales:

- Ante cualquier proyecto de exploración ${ }^{102}$ (cualquier intervención para ubicar un mineral) y explotación ${ }^{103}$ (cualquier operación que tenga por objeto la extracción o captación de los minerales yacentes en el suelo o subsuelo del área de la concesión) minera ${ }^{104}$ como, por ejemplo, la extracción

99 Corte IDH, Caso del Pueblo Saramaka vs. Surinam, Excepciones..., op. cit., párr. 194 c); Corte IDH, Caso del Pueblo Saramaka vs. Surinam. Interpretación..., op. cit.; República de Colombia, Corte Constitucional, Sentencia C-175 de 2009 de 18 de marzo de 2009.

100 En este sentido, el Consejo de Administración de la OIT en su $282^{a}$ reunión, noviembre de 2001, por medio de la Reclamación presentada en virtud del artículo 24 de la Constitución de la OIT, Colombia, GB.282/14/3, señaló que el Decreto 1320 que reglamenta la consulta en el país era incompatible con el Convenio 169 de la OIT por no haber sido consultado previamente a los pueblos.

101 оіт, Reclamación (artículo 24), 2006, Brasil, C169..., op. cit., párr. 50.

102 República de Bolivia, Sentencia Constitucional 2003/2010-R,..., op. cit.

103 Expediente Número 00-000543-0007-CO, Sala Constitucional de la Corte Suprema de Justicia de Costa Rica, Sentencia de Amparo 08019, Considerando V (8 sep. 2000).

104 República de Colombia, Corte Constitucional, Sentencias C-891 de 2002 (22 de octubre de 2002) y T-769 de 2009 (29 de octubre de 2009); Naciones Unidas, Asamblea General, A/ HRC /15/37/Add.7 de 17 de septiembre de 2010..., op. cit., párr. 38; República del Ecuador, Corte Constitucional, Quito, 18 de marzo de 2010, Sentencia n. ${ }^{\circ}$ 001-10-SIN-CC, Casos n. ${ }^{\circ}$ 0008-09-IN y 0011-09-IN (Acumulados), Juez constitucional ponente: Dr. Patricio Pazmiño Freire. 
de oro y plata ${ }^{105} \mathrm{y} / \mathrm{o}$ de yacimientos petroleros ubicados en territorios indígenas ${ }^{106} \mathrm{o}$ cualquier proyecto dentro de su territorio. ${ }^{107}$

- Licencias ambientales, ${ }^{108}$ diseño, elaboración y evaluación de los estudios de impacto ambiental, socio-económico y cultural, ${ }^{109}$ los resultados de los estudios previos de impacto social y ambiental, ${ }^{110}$ explotaciones forestales, ${ }^{111}$ plan de manejo ambiental para la erradicación de cultivos ilícitos ${ }^{112}$ o programa de erradicación de cultivos ilícitos ${ }^{113}$ de manera manual o por medio de fumigaciones, para el seguimiento y control de las obligaciones ambientales de una represa, ${ }^{114}$ plan de manejo de las áreas del Sistema de Parques Nacionales Naturales cuando se traslapan parques nacionales con territorios de pueblos indígenas.

105 Véase Comunidades del Pueblo Maya (Sipakepense y Mam) de los municipios de Sipacapa y San Miguel Ixtahuacán en el Departamento de San Marcos vs. Guatemala, Medidas Cautelares, Comisión Interamericana de Derechos Humanos MC 260-07, 20 de mayo de 2010.

106 República de Colombia, Corte Constitucional, Sentencia C-030 de 2008, 23 de enero de 2008; República de Bolivia, Sentencia Constitucional 0045/2006, Sucre, 2 de junio de 2006, Expediente: 2005-12440-25-RDI, Distrito: La Paz, Magistrada Relatora: Dra. Silvia Salame Farjat, Punto II. 5.2 consultado el 31 de enero de 2013, disponible en: http://www.tribunalconstitucional.gob.bo/resolucion14197.html

107 República de Bolivia, Sentencia Constitucional 2003/2010-R..., op. cit.

108 República de Colombia, Corte Constitucional, Sentencias: C-418 de 2002 (28 de mayo de 2002), SU-039 de 1997 (3 de febrero de 1997), y T-652 de 1998 (10 de noviembre de 1998). 109 República de Colombia, Corte Constitucional, Sentencia C-169 de 2001 (14 de febrero de 2001).

110 Corte IDH, Caso del Pueblo Saramaka vs. Surinam, Interpretación..., op. cit., párr. 16.

111 República de Colombia, Corte Constitucional, Sentencia T-955 de 2003 (17 de octubre de 2003).

112 República de Colombia, Corte Constitucional, Sentencia C-245 de 2004 (16 de marzo de 2004).

113 República de Colombia, Corte Constitucional, Sentencia SU-383 de 2003 (13 de mayo de 2003).

114 Véase Mercedes Julia Huenteao Beroiza y otras vs. Chile, Comisión Interamericana de Derechos Humanos. (11 de marzo de 2004), Informe n. ${ }^{\circ}$ 30/04 (Solución amistosa). 
- El proceso de delimitación, demarcación y otorgamiento de título colectivo del territorio, ${ }^{115}$ así como la elección y entrega de tierras alternativas de forma consensuada. ${ }^{116}$

- Administración de zonas. ${ }^{117}$

- Proyectos turísticos o eco-turísticos, portuarios, aéreos, urbanos o hidroeléctricas dentro de su territorio.

- Procesos de investigación científica en cuanto a recursos biológicos que involucre alguna o todas las actividades de colecta, recolecta, captura, caza, pesca, manipulación del recurso biológico y su movilización en el territorio nacional o investigación arqueológica.

- La construcción y ampliación de carreteras en territorios indígenas. ${ }^{118}$

- Cualquier restricción a los derechos de propiedad, particularmente respecto de planes o proyectos de desarrollo o inversión ${ }^{119}$ dentro de su territorio o que afecten el territorio, ${ }^{120}$ o proyectos de desarrollo ${ }^{121} \mathrm{o}$ de inversión.

115 Corte IDH, Caso del Pueblo Saramaka vs. Surinam, Excepciones..., op. cit., párr. 194; Corte IDH,. Caso del Pueblo Saramaka vs. Surinam, Interpretación..., op. cit., párr. 16; Corte IDH, Caso de la Comunidad Moiwana vs. Surinam, Excepciones Preliminares, Fondo, Reparaciones y Costas, Sentencia 15 de junio de 2005, Serie C n. ${ }^{\circ}$ 124. párr. 133; República de Colombia, Corte Constitucional, Sentencias: T-880 de 2006 (26 de octubre de 2006) y SU-383 de 2003 (13 de mayo de 2003).

116 Corte IDH, Caso Comunidad Indígena Sawhoyamaxa vs. Paraguay, Fondo, Reparaciones y Costas, Sentencia de 29 de marzo de 2006, Serie C n. ${ }^{\circ}$ 146, párr. 135; Corte IDH, Caso Comunidad Indígena Yakye Axa vs. Paraguay, Fondo Reparaciones y Costas, Sentencia 17 de junio de 2005, Serie C n. ${ }^{\circ}$ 125, párr. 151.

117 Véase Sector de la Población Nicaragüense de Origen Miskito vs. Nicaragua, Comisión Interamericana de Derechos Humanos, Caso n ${ }^{\circ} 7964$, Resolución sobre el Procedimiento de Solución Amistosa sobre la Situación de los Derechos Humanos de un Sector de la Población Nicaragüense de Origen Miskito (16 de mayo de 1984).

118 República de Colombia, Corte Constitucional, Sentencias: T-129 de 2011 (3 de marzo de 2011), SU-039 de 1997 (3 de febrero de 1997), T-428 de 1992 (24 de junio de 1992) y T-745 de 2010 de (14 de septiembre de 2010).

119 Naciones Unidas, Asamblea General. A/HRC/15/37/Add.7 de 17 de septiembre de 2010. Asamblea General..., op. cit., párr. 38.

120 Corte IDH, Caso del Pueblo Saramaka vs. Surinam, Interpretación..., op. cit., párr. 16.

121 Corte IDH, Caso Comunidad Indígena Sawhoyamaxa vs. Paraguay. Fondo, Reparaciones y Costas. Sentencia de 29 de marzo de 2006. Serie C n. ${ }^{\circ}$ 146. párr. 223 
- El reconocimiento legal de la capacidad jurídica colectiva. ${ }^{122}$

- Adopción de niños, niñas o adolescente indígenas. ${ }^{123}$

- Medidas contra la explotación laboral de la niñez indígena. ${ }^{124}$

- La adopción del sistema especial de educación de los grupos étnicos, ${ }^{125}$ así como programas de formación técnica, tecnológica y profesional.

- Medidas legislativas como leyes aprobatorias de tratados internacionales, ${ }^{126}$ leyes sobre el territorio, el Código o Estatuto en materia Ambiental, ${ }^{127}$ la Ley del Plan Nacional de Desarrollo, proyectos o programas que afecten específicamente a los grupos indígenas o los proyectos de obra, ${ }^{128}$ la Ley General Forestal o la Ley de Administración de Bosques Públicos, ${ }^{129}$ Estatuto de desarrollo Rural, ${ }^{130}$ normas que hagan referencia nominal a los

122 Corte IDH, Caso del Pueblo Saramaka vs. Surinam, Interpretación..., op. cit., párr. 16.

123 En el caso de Colombia corresponde al artículo 70 del Código de la Infancia y la Adolescencia (Ley 1098 de 2006).

124 onU, Declaración de las Naciones Unidas sobre los derechos de los pueblos indígenas (2007), Artículo 17.2.

125 República de Colombia, Corte Constitucional, Sentencia C-208 de 2007 (21 de marzo de 2007).

126 Conforme a lo establecido por la Convención de Viena sobre el derecho de los tratados de 1969 en su artículo 2.1.a) “se entiende por 'tratado' un acuerdo internacional celebrado por escrito entre Estados y regido por el derecho internacional, ya conste en un instrumento único o en dos o más instrumentos conexos y cualquiera que sea su denominación particular". En relación a la consulta de tratados, la Corte Constitucional colombiana estableció en la sentencia C-615 de 2009 (2 de septiembre de 2009) que "la consulta previa a las comunidades indigenas deberá llevarse a cabo antes de que el Presidente de la República remita el tratado y su ley aprobatoria al Senado. En tal sentido, los indigenas podrán ser consultados al momento de construir la posición negociadora colombiana ante el respectivo foro internacional, con el propósito de que las minorias aporten valiosos elementos de juicio al respecto y como expresión del cambio de paradigma respecto de las relaciones de los Estados con las minorías étnicas existentes dentro de su territorio" (resaltado fuera de texto original). 127 Naciones Unidas, Asamblea General. 17 de septiembre de 2010. A/HRC/15/37/Add.7..., op. cit., p. 12.

128 República de Colombia, Corte Constitucional, Sentencia C-461 de 2008 (14 de mayo de 2008).

129 OIT, Reclamación (artículo 24), 2006 Brasil, C169..., op. cit., párr. 41.

130 República de Colombia, Corte Constitucional, Sentencia C-175 de 2009 (18 de marzo de 2009). 
pueblos indígenas, así como las leyes laborales, ${ }^{131}$ de regalías, de restitución de tierras y de reparación de víctimas indígenas en casos de conflicto armado, leyes sobre ordenamiento territorial que afecten territorios indígenas, reformas agrarias, actos legislativos o actos reformatorios de la Constitución y decretos leyes. ${ }^{132}$

- Los proyectos de ley o consulta pre-legislativa, los cuales están diseñados para que se logre una concertación entre las comunidades y las instancias gubernamentales, lo que implica que las autoridades representativas ${ }^{133}$ de "aquellas deben (i) estar en la posibilidad de formular modificaciones y adiciones al proyecto de medidas legislativas propuestas por el Gobierno y (ii) de lograrse un acuerdo sobre la inclusión de esa modificación, que la misma tenga la potencialidad de hacer parte del texto definitivo de la ley". ${ }^{134}$

- Procesos de licitación estatal que afecten a pueblos indígenas. ${ }^{135}$

- Lugares de trascendencia étnico-histórica. ${ }^{136}$

- Medidas para garantizar la seguridad de los miembros. ${ }^{137}$

- El suministro de agua potable suficiente para el consumo y aseo personal de los miembros de la Comunidad. ${ }^{138}$

- La revisión y atención médica y psicosocial de todos los miembros de la comunidad, especialmente los niños, las niñas y ancianos,

131 República de Colombia, Corte Constitucional, Sentencia C-030 de 2008 (23 de enero de 2008).

132 República de Colombia, Corte Constitucional, Sentencia C-702 de 2010 (6 de septiembre de 2010).

133 оाт, Reclamación (artículo 24), 2006, Brasil, C169..., op. cit., párr. 42.

134 República de Colombia, Corte Constitucional, Sentencia C-175 de 2009 (18 de marzo de 2009).

135 Sala Constitucional de la Corte Suprema de Justicia de Costa Rica (8 de septiembre de 2000). Sentencia de Fondo. Recurso de amparo. Exp.: 00-000543-0007-CO. Redactor. Luis Fernando Solano.

136 República de Chile, Corte de Apelaciones de Concepción, Chile. Concepción, (10 de agosto de 2010), consultado el 31 de enero de 2013, disponible en: http:/ /www.politicaspublicas.net/panel/jp/676-concepcion-rol289-2010.html

137 Corte IDH, Caso de la Comunidad Moiwana vs. Surinam, Excepciones..., op. cit., párr. 212

138 Corte IDH, Caso Comunidad Indígena Xákmok Kásek. vs. Paraguay. Fondo, Reparaciones y Costas. Sentencia de 24 de agosto de 2010 Serie C n. ${ }^{\circ} 214$. párr. 301 y 302. 
acompañadas de la realización periódica de campañas de vacunación y desparasitación que respeten sus usos y costumbres. ${ }^{139}$

- Atención médica especial a las mujeres que se encuentren embarazadas, tanto antes del parto como durante los primeros meses después de este, así como al recién nacido. ${ }^{140}$

- Entrega de alimentos en calidad y cantidad suficientes para asegurar una alimentación adecuada. ${ }^{141}$

- La instalación de letrinas o cualquier tipo de servicio sanitario adecuado en el asentamiento de la comunidad. ${ }^{142}$

- Dotación a las escuelas de los materiales y recursos humanos necesarios para garantizar el acceso a la educación básica para los niños y niñas de la comunidad, prestando especial atención a que la educación impartida respete sus tradiciones culturales y garantice la protección de su lengua propia. ${ }^{143}$

- Planes de urgencia de lenguas nativas en peligro de extinción y proyectos en la materia. ${ }^{144}$

- La convocatoria a elecciones como un elemento de juicio para determinar la existencia de una prolongación injustificada de la situación de violación de los derechos electorales de la comunidad. ${ }^{145}$

- Otorgamiento de una justa indemnización, ${ }^{146}$ que no debe confundirse con las compensaciones ambientales, así como que la determinación de dichos beneficiarios deberá ser realizada en consulta con el pueblo implicado y no unilateralmente por el Estado en el supuesto de que surgiera algún conflicto interno entre los miembros del pueblo sobre los beneficiarios, esto debe

139 Ibíd.

140 Ibíd.

141 Ibíd.

142 Ibíd.

143 Ibíd.

144 Por ejemplo, en Colombia artículos 12 y 21 de la Ley 1381 de 2010 sobre reconocimiento, fomento, protección, uso, preservación y fortalecimiento de las lenguas de los grupos étnicos en el país y sobre sus derechos lingüísticos y los de sus hablantes.

145 Organización Internacional del Trabajo (OIT), Aplicación del Convenio n. ${ }^{\circ} 169$ de la OIT por tribunales nacionales e internacionales en América Latina (2009). p. 167.

146 Corte IDH, Caso Comunidad Indígena Yakye Axa vs. Paraguay. Fondo Reparaciones y Costas. Sentencia 17 de junio de 2005. Serie C n. ${ }^{\circ}$ 125. párr., 151. 
ser resuelto por el propio pueblo de conformidad con sus propias costumbres y normas tradicionales, y no por el Estado o una Corte o un tribunal. ${ }^{147}$

El tercer aspecto importante sobre la consulta es determinar el sujeto de esta, que es el pueblo indígena como colectividad. El Estado no debe decidir sobre quién o quiénes representarán al pueblo implicado, sino son ellos mismos los que en cada proceso de consulta según sus costumbres y usos deben decidir sus representantes. ${ }^{148}$ Es el mismo pueblo quien informara al Estado sus representantes en cada uno de los procesos de consulta. ${ }^{149}$ Por consiguiente, es incompatible el establecimiento mediante leyes fijas de los representantes de un pueblo indígena determinado, y en consecuencia obviar el autogobierno al interior de las comunidades.

Además, el Estado debe garantizar que las comunidades, autoridades y líderes indígenas en situación de desplazamiento sean también sujetos de la consulta previa o, en su defecto, la participación de las organizaciones que abogan por los derechos de los pueblos indígenas a nivel regional y nacional..$^{150}$

Igualmente, la consulta debe abarcar en criterio de la OIT por lo menos los siguientes aspectos: ${ }^{151}$

a. la naturaleza, envergadura, ritmo, reversibilidad y alcance de cualquier proyecto o actividad propuesto

b. la razón o las razones o el objeto del proyecto y/o la actividad

c. la duración del proyecto o la actividad

d. la ubicación de las áreas que se verán afectadas;

e. una evaluación preliminar de los probables impactos económicos, sociales, culturales y ambientales, incluso los posibles riesgos, y una distribución de beneficios justa y equitativa en un contexto que respete el principio de precaución

147 Corte IDH, Caso del Pueblo Saramaka vs. Surinam, Interpretación..., op. cit., párr. 23 a 26. 148 Ibíd., párr. 18, 19 y 22.

149 Ibíd., párr. 18 y 19.

150 Organización Nacional Indígena de Colombia (ONIC), El derecho fundamental a la consulta previa de los pueblos indigenas en Colombia, Antropos, Bogotá, 2011 pp. 30 y 31.

151 OIT, "Los derechos de los pueblos indígenas y tribales en la práctica", Una guia sobre el Convenio, n. ${ }^{\circ} 169$ de la OIT’, 2009, p. 63. 
f. el personal que probablemente intervenga en la ejecución del proyecto propuesto, incluso pueblos indígenas, personal del sector privado, instituciones de investigación, empleados gubernamentales y demás personas

g. los procedimientos que puede entrañar el proyecto.

Además, la ONU ha determinado la insuficiente participación de los grupos indígenas en las decisiones que afectan su territorio y la distribución de los recursos naturales en sus territorios, sus culturas y sus tradiciones. ${ }^{152}$ Cabe resaltar que la consulta previa, libre e informada debe ser realizada, supervisada y garantizada exclusivamente por el Estado, no por la empresa, pero puede tener la participación de las empresas implicadas en un proyecto, en caso contrario, el Estado omitiría la protección de personas que requieren especial atención.

En consecuencia, las empresas no pueden ni deben llevar a cabo procesos de consulta que sustituyan las obligaciones que corresponden a las autoridades competentes en esta materia, sin involucrar activamente estas autoridades y sin su supervisión directa, ${ }^{153}$ proporcionando, por ejemplo, una orientación efectiva a las empresas sobre la manera de respetar los derechos humanos en todas sus operaciones. ${ }^{154}$ Asimismo, con el fin de identificar, prevenir, mitigar y dar cuenta de cómo responder a sus impactos negativos en los derechos humanos, las empresas deben cumplir con la debida diligencia en derechos humanos. ${ }^{155}$

Por último, cabe destacar algunos obstáculos detectados en casos como el argentino para el acceso a la justicia de pueblos indígenas, por ejemplo: falta de peritos especializados en materia indígena, desconocimiento de las instituciones indígenas por parte de los operadores judiciales y de los medios que los propios pueblos indígenas tienen para la resolución de conflictos,

152 U.N. GAOR, "Report of the Committee on the Elimination of Racial Discrimination", $50^{a}$ Sesión, Tema 103 de la agenda, pára. 536, UN- Doc. A/50/18 (1995).

153 Naciones Unidas, Observaciones preliminares del Relator Especial de pueblos indígenas sobre su visita a Guatemala, consultado el 31 de enero de 2013, disponible en: http:/ / www. ohchr.org/en/NewsEvents/Pages/DisplayNews.aspx?NewsID=10173\&LangID=S. República de Colombia, Corte Constitucional, Sentencia C-175 de 2009 (18 de marzo de 2009).

154 United Nations, General Assembly, A/HrC/17/31, marzo 21 de 2011. Principio 3(c), consultado el 31 de enero de 2013, disponible en: http:/ /www.ohchr.org/documents/issues/ business/A.HRC.17.31.pdf

155 Ibíd., Principio 18. 
extensa duración en los procesos judiciales, ausencia e insuficiencia de intérpretes y traductores estables de lenguas indígenas que intervengan desde la etapa de consulta y en todas las etapas procesales posteriores, inexistencia de procesos judiciales especializados para la tutela de derechos indígenas colectivos, escasez de abogados especializados en derechos indígenas y de abogados indígenas, desconocimiento por parte de los operadores judiciales de los derechos reconocidos a los pueblos indígenas, complejidad de los conflictos judiciales planteados y dificultades en el cumplimiento efectivo de las sentencias, distancia entre los servicios de justicia y lugar de residencia de las pueblos indígenas, desconocimiento de los lugares y/o ámbitos a donde deben acudir por información. ${ }^{156}$

\section{2. ¿Derecho a la consulta previa vs. consentimiento de los pueblos indígenas?}

Mucha confusión ${ }^{157}$ se ha generado en relación al alcance, la aplicación y los efectos del consentimiento. ${ }^{158}$ En efecto, existe una diferencia entre "consulta" y "consentimiento", ${ }^{159}$ entendiendo por este último en su sentido corriente como una manifestación de voluntad, expresa o tácita, por la cual un sujeto se vincula jurídicamente. ${ }^{160}$ En consecuencia, el llamado derecho al veto u oposición vinculante de parte de los pueblos indígenas para no reali-

156 Ministerio Público de la Defensa de Argentina, Acceso a la justicia de los pueblos indígenas. (2010) pp. 33, 37, 46, 55, 60, 66, 72, 74, 78, 93, 102.

157 Por ejemplo, no fueron claros los fundamentos legales para diferenciar consulta y consentimiento en casos como de las Comunidades indígenas mayas del distrito de Toledo c. Belice (CIDH, Informe n. ${ }^{\circ}$ 40/04 (Fondo), 12 de octubre de 2004), y en el Caso Mary y Carrie Dann c. Estados Unidos (CIDH,. Informe n. ${ }^{\circ}$ 75/02, Fondo, 27 de diciembre de 2002).

158 En este sentido se debe subrayar que "la Comisión considera que los principios jurídicos internacionales generales aplicables en el contexto de los derechos humanos de los indígenas incluyen: [...] y en los casos en que los derechos de propiedad y uso de los pueblos indígenas deriven de derechos previamente existentes a la creación de sus Estados, el reconocimiento por los Estados de los títulos permanentes e inalienables de los pueblos indígenas y a que ese título sea modificado únicamente por consentimiento mutuo entre el Estado y el pueblo indígena respectivo" (resaltado fuera del texto), Caso Mary y Carrie Dann c. Estados Unidos (CIDH. Informe n..$^{\circ}$ 75/02, Fondo, 27 de diciembre de 2002, párr. 130).

159 República de Colombia, Corte Constitucional, Sentencia T-769 de 2009 (29 de octubre de 2009).

160 Diccionario de la Real Academia de la Lengua Española, significado de la palabra consentimiento consultado el 31 de enero de 2013, disponible en: http:/ / buscon.rae.es/draeI/ SrvltConsulta?TIPO_BUS=3\&LEMA= consentimiento 
zar determinada medida que los afecta no es aplicable en casos de consulta, pero sí cuando se requiere consentimiento.

En todo caso, en desarrollo del derecho-deber de consulta previa una de sus finalidades es lograr el consentimiento ${ }^{161}$ del pueblo indígena implicado. ${ }^{162}$ Cabe destacar, que

[...] la consulta previa se fundamenta en el derecho a la participación, la cual en últimas no implica la toma definitiva de la decisión por parte de los pueblos indígenas, contrario a lo que sucede con el consentimiento libre, previo e informado que se fundamenta en el principio a la libre determinación de los pueblos, en virtud del cual pueden establecer su condición política, lograr libremente su desarrollo económico, social y cultural, es decir que pueden decidir sobre los proyectos que logren afectarles y además les permita a los pueblos indígenas tomar la decisión final directamente". 163

En este sentido, la Resolución 2625 de la Asamblea General de la ONU establece como formas del ejercicio del derecho a la libre determinación de los pueblos el establecimiento de un Estado soberano e independiente, la libre asociación o integración con un Estado independiente o la adquisición de cualquier otra condición política, decidida de forma libre por un pueblo no implica necesariamente un interés secesionista del Estado.

161 De acuerdo a Esther Sánchez Botero "Aprobar o desaprobar son sinónimas de consentimiento. En este sentido el consentimiento se formaliza siempre en interacción con otros que proponen o presentan algo que puede y debe ser examinado [...] Tiene límites dentro de algunos Estados ya [que] no siempre es previsible que se llegue a tolerar", "Consulta, participación y consentimiento en el marco de la Declaración de Naciones Unidas“, p. 54, en RELAju y ANH, Consulta previa. Principios, enfoque metodológico e instrumentalización. VI Congreso de Antropología Jurídica, 2008.

162 Artículo 6 numeral 2 del Convenio 169 de la Оіт.

163 Rodríguez, G. A., "El papel de la consulta previa en la pervivencia de los pueblos indígenas y demás grupos étnicos de Colombia”, pp. 71 y 72; Instituto Latinoamericano de Servicios Legales Alternativos, "El derecho a la consulta previa en América Latina: del reconocimiento formal a la exigibilidad de los derechos de los pueblos indígenas", en: El Otro Derecho, n. ${ }^{\circ} 40$ (jun, 2009), disponible en: http://ilsa.org.co:81/biblioteca/dwnlds/od/elotrdr040/od40gloria.pdf, consultado el 29 de abril de 2013; Rodríguez, G. A., "La consulta previa en pueblos indígenas y comunidades afrodescendientes en Colombia" (2010) pp. 69 y 70, disponible en: http://www.urosario.edu.co/urosario_files/1f/1fd9b49f-b717-4dc1-8875-657612776cff. pdf, consultado el 29 de abril de 2013. 
Por consiguiente, el consentimiento de los pueblos indígenas en la actualidad sí es vinculante pero de forma excepcional, a pesar de que tal vez en el futuro podría ser la regla general pese a la existencia de álgidas controversias en este sentido. Cabe resaltar que el Relator Especial sobre pueblos indígenas señaló que lamentaba que en muchas situaciones el debate sobre el deber de celebrar consultas y el consentimiento libre, previo e informado se haya planteado en torno a si los pueblos indígenas tienen o no un poder de veto que pueden esgrimir para detener los proyectos de desarrollo. ${ }^{164}$ Por lo tanto, el uso del lenguaje, haciendo referencia al derecho al veto en sí mismo, es autoritario y no permite un diálogo intercultural ni tiene el propósito de obtener el consentimiento en materia de consulta.

Así, el Relator de Naciones Unidas consideró que plantear de esa manera el debate no se ajusta al espíritu ni al carácter de la consulta y el consentimiento según se han desarrollado en las normas internacionales de derechos humanos y se han incorporado en la Declaración. ${ }^{165}$ Por otra parte, en todo caso, de llegar a un acuerdo entre las partes como resultado de la consulta, este tiene efectos vinculantes porque en derecho internacional e interno son aplicables los principios de buena fe y pacta sunt servanda — todo acuerdo debe ser cumplido-.

Sin embargo, para ilustrar mejor expondré ejemplos de medidas que requieren consentimiento, teniendo presente que el derecho al consentimiento libre, previo e informado es parte integrante del derecho a la libre determinación ${ }^{166}$ y en este sentido a las prioridades en su desarrollo. Los ejemplos que requieren el consentimiento de los pueblos indígenas son:

- Cuando se trate de planes de desarrollo o de inversión a gran escala ${ }^{167}$ que tendrían un mayor impacto dentro del territorio del

164 Naciones Unidas, "Una cuestión fundamental: El deber de celebrar consultas con los pueblos indígenas", capítulo principal del informe presentado por el relator James Anaya ante el Consejo de Derechos Humanos, $12^{\circ}$ período de sesiones, septiembre de 2009 , punto 41. párr. 47 y 48.

165 Anaya, James. Una Cuestión Fundamental: El Deber de celebrar consultas con los pueblos indígenas. párr. 47 y 48. Ibíd.

166 Naciones Unidas, Asamblea General, Consejo de Derechos Humanos, Informe definitivo del Estudio sobre los pueblos indígenas y el derecho a participar en la adopción de decisiones, 17 de agosto de 2011, p. 21.

167 Corte IDH, Caso del Pueblo Saramaka vs. Surinam, Excepciones..., op. cit., párr. 134; Asimismo, la Corte Interamericana cita en su párr. 136 lo siguiente: "El CEDR ha observado que 
pueblo implicado o proyectos de gran impacto. ${ }^{168}$ Por ejemplo, cuando afecte, inevitablemente, a otros recursos naturales necesarios para la subsistencia de dicho pueblo, como los canales navegables, o todos aquellos recursos naturales cuya extracción afectaría, inevitablemente, otros recursos que son vitales para su modo de vida. ${ }^{169}$ Sin embargo, es necesario desarrollar qué se entiende por "gran escala"170 o "mega proyectos" con criterios claros y objetivos.

- Los proyectos que tengan un impacto significativo sobre los derechos de los pueblos indígenas. Aquellos proyectos que representan un alto impacto social, cultural y ambiental en una comunidad étnica, que conlleve poner en riesgo la existencia de la misma, entre otros ejemplos, ${ }^{171}$ tales como las represas mencionadas con

'[e]n cuanto a la explotación de los recursos que yacen en el subsuelo en tierras tradicionales de comunidades indígenas, el Comité observa que la mera consulta con estas comunidades no es suficiente para cumplir con los requisitos establecidos por el Comité en su recomendación general XXIII sobre los derechos de los pueblor indígenas. El Comité, por lo tanto, recomienda que se obtenga el consentimiento previo e informado de dichas comunidades', Comité de Naciones Unidas para la Eliminación de la Discriminación Racial, Consideraciones de los Informes presentados por los Estados Partes conforme al artículo 9 de la Convención, Observaciones Finales respecto del Ecuador, sesión sesenta y dos, 2003, ONU Doc. CEDR/C/62/CO/2, 2 de junio de 2003, párr. 16". Véase República de Colombia, Corte Constitucional, Sentencia T-129 de 2011 de 3 de marzo de 2011. M.P. Jorge Iván Palacio Palacio, p. 73; República de Colombia. Corte Constitucional. Sentencia T-769 de 2009 de 29 de octubre de 2009; República de Bolivia. Sentencia Constitucional 2003/2010-R..., op. cit.

168 Si bien la Corte Interamericana de Derechos Humanos en un caso posterior (Caso Pueblo Indígena Kichwa de Sarayaku vs. Ecuador) no desarrolló ni aplicó las medidas que requieren consentimiento como ya lo había hecho con anterioridad (Caso del Pueblo Saramaka vs. Surinam) se debe tener en cuenta que el precedente sigue siendo aplicable con fundamento en el principio pro-personae, y el principio pro-indigena.

169 Corte IDH, Caso del Pueblo Saramaka vs. Surinam, Excepciones..., op. cit., párr. 134 y 155; República de Colombia, Corte Constitucional, Sentencia C-461 de 2008 (14 de mayo de 2008).

170 Un indicador que podría ayudar a determinar es la necesidad de obtener una licencia ambiental conforme a la legislación interna aunque hay que tener en cuenta que no se pueden excluir otras actividades que no requieren licencia y que pueden constituir proyectos a gran escala.

171 República de Colombia, Corte Constitucional, Sentencia T -129 de 3 de marzo de 2011, p. 76. La Corte Constitucional se fundamentó con la Declaración realizada el 26 de mayo de 2010 ante el Congreso de la República del Perú del Relator Especial sobre los Derechos Humanos y Libertades fundamentales de los indígenas, James Anaya. 
anterioridad, o, por ejemplo, una mina. ${ }^{172}$ Además, para determinar el impacto, algunos autores señalan que se trata de un proyecto de este tipo cuando este genere efectos como "i) la pérdida de territorios y tierra tradicional, ii) el desalojo, iii) la migración y el posible reasentamiento, iv) el agotamiento de recursos necesarios para la subsistencia física y cultural, v) la destrucción y contaminación del ambiente tradicional, vi) la desorganización social y comunitaria, vii) impactos sanitarios y nutricionales negativos y de larga duración o vii) abuso y violencia". ${ }^{173}$

- Traslados de las tierras que ocupan y su reubicación ${ }^{174}$ (Arts. 16.2 del Convenio 169 de la OIT y 10 de la Declaración de las Naciones Unidas sobre los Derechos de los Pueblos Indígenas). ${ }^{175}$

- Almacenamiento o eliminación de materiales peligrosos o tóxi$\cos ^{176}$ en las tierras o territorios de los pueblos indígenas (Art. 29 de la Declaración de la ONU sobre derechos de los pueblos indígenas). ${ }^{177}$

- Medidas que tengan como resultado el quebrantamiento de los valores y de las instituciones de dichas poblaciones a menos que puedan ser reemplazados adecuadamente y con el consentimiento de los grupos interesados (Art. 4 b) del Convenio 107 de la OIT.

- En relación a los conocimientos, las innovaciones y las prácticas de las comunidades indígenas y locales que entrañen estilos tradicionales de vida pertinentes para la conservación (Convenio sobre la diversidad biológica (1992), artículo 8 j).

172 Naciones Unidas, Observaciones preliminares del Relator Especial de pueblos indígenas sobre su visita a Guatemala, consultado el 31 de enero de 2013, disponible en: http:/ /www. ohchr.org/en/NewsEvents/Pages/DisplayNews.aspx?NewsID=10173\&LangID=S

173 Galvis, María Clara. Consulta, consentimiento y veto, en Aportes DPLF, Revista de la Fundación para el Debido Proceso Legal Número 14, Año 3, septiembre de 2010, p. 11.

174 Podría incluir el traslado del pueblo indígena como consecuencia de la falta de reconocimiento de su territorio ancestral.

175 República de Bolivia. Sentencia Constitucional 2003/2010-R..., op. cit.; República de Colombia. Corte Constitucional. Sentencia T- 129 de 2011 de 3 de marzo de 2011, p. 76. La Corte constitucional se fundamentó con la Declaración realizada el 26 de mayo de 2010 ante el Congreso de la República del Perú del Relator Especial sobre los derechos humanos y libertades fundamentales de los indígenas, James Anaya.

176 Ibíd. Sentencia T-129 de 2011 de 3 de marzo de 2011, p. 76.

177 República de Bolivia. Sentencia Constitucional 2003/2010-R..., op. cit. 
- En casos de pueblos de aislamiento voluntario y contacto inicial por la alta probabilidad de sus efectos adversos por contacto y por el alto riesgo de extinción física y cultural.

- Proyectos de represas que afectan a pueblos indígenas y tribales. ${ }^{178}$ Un ejemplo de ello es la situación de las cien mil personas chakma desplazadas por la represa hidroeléctrica Kaptai en las Colinas de Chittagong, Bangladesh. ${ }^{179}$

- Los recursos genéticos de los pueblos indígenas (art. 15 n. ${ }^{\circ} 5$ del Convenio sobre la diversidad biológica de 1992).

- Cuando se quieran realizar actividades militares en el territorio indígena salvo por razones de interés público o se haya llegado a un acuerdo libremente con los pueblos indígenas (art. 30.1 de la Declaración de las Naciones Unidas sobre los Derechos de los Pueblos Indígenas).

No obstante, cabe señalar que todas las medidas mencionadas que requieren consentimiento no podrán ser obligatorias a menos que se demuestre un conflicto de derechos en donde la única medida posible luego de un análisis objetivo, de razonabilidad y proporcionalidad involucre un interés general mayor, y que podría suceder por el crecimiento desmedido de la población.

En conclusión, la consulta previa, libre e informada encuentra fundamento en diversos instrumentos legales internacionales así como en aportes en otras fuentes que han avanzado hacia la protección diferencial de los pueblos indígenas, replanteando la relación entre el Estado y los pueblos indígenas a la importancia del diálogo y la garantía de derechos para la pervivencia de estos pueblos. Asimismo, por medio de ejemplos se intentó aclarar y evidenciar la existencia de consentimiento en ciertos casos y la necesidad de desarrollar el tema, generando en este aspecto que los pueblos indígenas sean sujetos plenos de derechos para decidir de acuerdo a su cosmovisión, y determinar su modo de vida y su desarrollo colectivo.

178 World Commission on Dams, Dams and Development, Report of the World Commission on Dams noviembre de 2000), p. 34.

179 Ibíd. p. 111. 


\section{Referencias bibliográficas}

Anaya, J., “Indigenous peoples' participatory rights in relation to Decisions about natural resource extraction: the More fundamental issue of what rights indigenous Peoples have in lands and resources", Arizona Journal of International \& Comparative Law, Vol. 22, n. ${ }^{\circ} 1$.

Banco Interamericano de Desarrollo, Política operativa sobre pueblos indígenas y Estrategia para el Desarrollo indígena (julio 2006).

Banco Mundial, Directriz OD 4.20

Banco Mundial, Manual de Operaciones, 2.34.

Banco Mundial, Manual de Operaciones del Banco Mundial, Políticas Operaciones OP 4.10 (julio de 2005).

Banco Mundial, Política Operacional OP 4.10 y Normas de Procedimiento del Banco.

CAN, Carta Andina para la Promoción y Protección de los Derechos Humanos artículo 39, Guayaquil, 26 de julio de 2002), consultado el 31 de enero de 2013, disponible en: http:/ /www.comunidadandina.org/ documentos/actas/cart_DDHH.htm

CARCR, Observaciones individuales sobre el Convenio 169 de la OIT a Guatemala, Conferencia Internacional del Trabajo, 97 reunión, 2008.

CIDH, Caso Mary y Carrie Dann c. Estados Unidos, Informe n. ${ }^{\circ} 75 / 02$, Fondo, 27 de diciembre de 2002).

$\mathrm{CIDH}$, Comunidades indígenas mayas del distrito de Toledo c. Belice, Informe n. ${ }^{\circ}$ 40/04, Fondo, 12 de octubre de 2004.

CIDH, Comunidad San Vicente Los Cimientos vs. Guatemala, Caso 11.197, Informe n. ${ }^{\circ}$ 68/03 (solución amistosa), 10 de octubre de 2003.

$\mathrm{CIDH}$, Derechos de los pueblos indígenas y tribales sobre sus tierras ancestrales y recursos naturales, Normas y Jurisprudencia del Sistema Interamericano de Derechos Humanos, OEA/Ser.L/V/II. Doc. 56/09, 30 diciembre 2009.

CIDH. Medida Cautelar. MC 382/10 - Comunidades Indígenas de la Cuenca del Río Xingú, Pará, Brasil (otorgada el 1 de abril de 2011).

CIDH, Sector de la Población Nicaragüense de Origen Miskito vs. Nicaragua, Caso n. ${ }^{\circ}$ 7964, Resolución sobre el Procedimiento de Solución Amistosa sobre la Situación de los Derechos Humanos de un Sector de la Población Nicaragüense de Origen Miskito, 16 de mayo de 1984.

Colombia y el Examen Periódico Universal de Derechos Humanos (EPU) ante el Consejo de Derechos Humanos de las Naciones Unidas: Experiencias, avances y desafíos, p. 28, consultada el 29 de Abril de 2013, 
disponible en: http://lib.ohchr.org/HRBodies/UPR/Documents/ Session3/CO/Colombia_UPR.pdf).

Combacau, J. y Sur, S., Droit international public, Montchrestien, París, 2006. Comité de Naciones Unidas para la Eliminación de la Discriminación Racial, Consideraciones de los Informes presentados por los Estados Partes conforme al artículo 9 de la Convención, Observaciones Finales respecto del Ecuador (sesión sesenta y dos, 2003, ONU Doc. CERD/C/62/ CO/2, 2 de junio de 2003.

Congreso de la República de Colombia, Ley 1381 de 2010. Congreso de la República de Colombia, Ley 1098 de 2006 (Código de la Infancia y la Adolescencia).

Consejo de Administración de la OIT en su 282 ${ }^{\mathrm{a}}$ reunión, noviembre de 2001, por medio de la Reclamación presentada en virtud del artículo 24 de la Constitución de la OIT, Colombia, GB.282/14/3.

Convención Americana sobre Derechos Humanos de 1969.

Convención de Viena sobre Derechos de los Tratados, 1969.

Corte IDH, Caso Almonacid Arellano y otros vs. Chile, Excepciones Preliminares, Fondo, Reparaciones y Costas, Sentencia de 26 de septiembre de 2006, Serie C n. ${ }^{\circ} 154$.

Corte IDH, Caso Comunidad Indígena Sawhoyamaxa vs. Paraguay, Fondo, Reparaciones y Costas, Sentencia de 29 de marzo de 2006, Serie C n. ${ }^{\circ} 146$.

Corte IDH, Caso Comunidad Indígena Xákmok Kásek vs. Paraguay, Fondo, Reparaciones y Costas, Sentencia de 24 de agosto de 2010, Serie C n. ${ }^{\circ} 214$.

Corte IDH, Caso Comunidad Indígena Yakye Axa vs. Paraguay, Fondo, Reparaciones y Costas, Sentencia 17 de junio de 2005, Serie C n. ${ }^{\circ} 125$.

Corte IDH, Caso de la Comunidad Mayagna (Sumo) Awas Tingni vs. Nicaragua, Fondo, Reparaciones y Costas, Sentencia de 31 de agosto de 2001, Serie C n. ${ }^{\circ} 79$.

Corte IDH, Caso de la Comunidad Moiwana vs. Surinam, Excepciones Preliminares, Fondo, Reparaciones y Costas, Sentencia 15 de junio de 2005, Serie C n. ${ }^{\circ} 124$.

Corte IDH, Caso de los "Niños de la Calle" (Villagrán Morales y otros) vs. Guatemala, Fondo, Sentencia de 19 de noviembre de 1999, Serie C n. ${ }^{\circ} 63$.

Corte IDH, Caso Gelman vs. Uruguay, Fondo y Reparaciones, Sentencia de 24 de febrero de 2011, Serie C n. ${ }^{\circ} 221$. 
Corte IDH, Caso del Pueblo Saramaka vs. Surinam, Excepciones Preliminares, Fondo, Reparaciones y Costas, Sentencia de 28 de noviembre de 2007, Serie C n. ${ }^{\circ} 172$.

Corte IDH, Caso del Pueblo Saramaka vs. Surinam, Interpretación de la Sentencia de Excepciones Preliminares, Fondo, Reparaciones y Costas, Sentencia de 12 de agosto de 2008, Serie C n. ${ }^{\circ} 185$.

Corte IDH, Caso Pueblo Indígena Kichwa de Sarayaku vs. Ecuador, Fondo y Reparaciones, Sentencia de 27 de junio de 2012, Serie C n. 245.

Corte IDH, Caso Radilla Pacheco vs. México, Excepciones Preliminares, Fondo, Reparaciones y Costas, Sentencia de 23 de noviembre de 2009, Serie C n. ${ }^{\circ} 209$.

Corte IDH, Caso Velásquez Rodríguez vs. Honduras, Fondo, Sentencia de 29 de julio de 1998 , Serie $\mathrm{C}$ n. ${ }^{\circ} 4$.

Diccionario de la Real Academia Española.

Galvis, M. C., "Consulta, consentimiento y veto", en Aportes DPLF, Revista de la Fundación para el Debido Proceso Legal, n. ${ }^{\circ}$ 14, año 3, septiembre de 2010.

Gómez Rojas, J. F., "Argument Analysis of the Position of Colombia Regarding the UN Declaration on the Rights of Indigenous Peoples, 16 International Law, Revista Colombiana de Derecho Internacional, 143-176 (2010). Consultada el 29 de abril de 2013, disponible en: http:/ / www. scielo.org.co/pdf/ilrdi/n16/n16a06.pdf

ICJ. Fisheries Case, United Kingdom v. Norway, Judgment of December $18^{\text {th }}, 1951$.

Ministerio Público de la Defensa de Argentina, Acceso a la justicia de los pueblos indígenas, 2010.

Naciones Unidas, Asamblea General, Consejo de Derechos Humanos, Informe definitivo del Estudio sobre los pueblos indígenas y el derecho a participar en la adopción de decisiones, 17 de agosto de 2011.

Naciones Unidas, Asamblea General, A/HrC/12/34 de 15 de julio de 2009, Consejo de Derechos Humanos, $12^{\circ}$ período de sesiones, Tema 3 de la agenda, "Promoción y protección de todos los derechos humanos, civiles, políticos, económicos, sociales y culturales, incluido el derecho al desarrollo", Informe del Relator Especial sobre la situación de los derechos humanos y las libertades fundamentales de los indígenas.

Naciones Unidas, Asamblea General, 17 de septiembre de 2010, A/ HRC/15/37/Add.7, Observaciones sobre los avances y desafíos en la implementación de las garantías de la Constitución Política del Ecuador sobre los derechos de los pueblos indígenas. 
Naciones Unidas, Observaciones preliminares del Relator Especial de pueblos indígenas sobre su visita a Guatemala, consultado el 31 de enero de 2013, disponible en: http://www.ohchr.org/en/NewsEvents/ Pages/DisplayNews.aspx?NewsID $=10173 \&$ LangID $=S$

Naciones Unidas, Pacto Internacional de derechos civiles y políticos, CCPR/ C/95/D/1457/2006 de 24 de abril de 2009. Comité de Derechos Humanos, $95^{\circ}$ período de sesiones, 16 de marzo a 3 de abril de 2009, Comunicación n 1457/2006, presentada por Ángela Poma Poma (representada por el abogado Tomás Alarcón), Estado Parte: Perú.

Naciones Unidas, "State of the World's Indigenous Peoples". Notas descriptivas, eEnero de 2010), consultado el 31 de enero de 2013, disponible en: http://www.un.org/esa/socdev/unpfii/documents/ SOWIP_fact_sheets_ES.pdf

Office of the High Commissioner for Human Rights CERD, General Recommendation n. ${ }^{\circ} 23$ : indigenous peoples: 18/08/1997, párr. 4(d).

Naciones Unidas, "Una cuestión fundamental: El deber de celebrar consultas con los pueblos indígenas", capítulo principal del informe presentado por el relator James Anaya ante el Consejo de Derechos Humanos, $12^{\circ}$ período de sesiones, septiembre de 2009.

OIT, Convenio 107 de 1957.

OIT, Convenio 169 de 1989.

OIT, Estados miembros, consultado el 31 de enero de 2012, disponible en: http://www.ilo.org/public/english/standards/relm/country.htm

OIT, "Los derechos de los pueblos indígenas y tribales en la práctica", Una guía sobre el Convenio n. ${ }^{\circ} 169$ de la OIT. (2009).

OIT, Ratificaciones y denuncias del Convenio n. ${ }^{\circ} 107$ de la OIT, consultado el 31 de enero de 2012, disponible en: http://www.ilo.org/ilolex/ cgi-lex/ratifcs.pl?C107

OIT, Reclamación (artículo 24), Reclamación (artículo 24), 2006, Brasil, C169, Informe del Comité encargado de examinar la reclamación en la que se alega el incumplimiento por Brasil del Convenio sobre pueblos indígenas y tribales, 1989 (n. ${ }^{\circ} 169$ ), presentada en virtud del artículo 24 de la Constitución de la OIT por el Sindicato de Ingenieros del Distrito Federal (SENGE/DF).

OIT, Sobre el Convenio n. ${ }^{\circ} 107$ de la OIT, consultado el 31 de enero de 2012, disponible en: http://www.ilo.org/indigenous/Conventions/no107/ lang--es/index.htm

ONU, Declaración de las Naciones Unidas sobre los derechos de los pueblos indígenas. 
ONU, Foro Permanente para cuestiones indígenas, Declaración de Naciones Unidas sobre los derechos de los pueblos indígenas, consultada el 29 de abril de 2013, disponible en: http://social.un.org/index/indigenouses/Portada/Declaraci\%C3\%B3n.aspx

Organización Internacional del Trabajo (OIT), Aplicación del Convenio n. ${ }^{\circ}$ 169 de la OIT por tribunales nacionales e internacionales en América Latina, 2009.

Organización Nacional Indígena de Colombia (ONIC), El derecho fundamental a la consulta previa de los pueblos indigenas en Colombia, Antropos, Bogotá, 2011.

RELAju y ANH, "Consulta previa. Principios, enfoque metodológico e instrumentalización”, VI Congreso de Antropología Jurídica, 2008.

Relatoría Especial para la Libertad de Expresión, Comisión Interamericana de Derechos Humanos, El Derecho de Acceso a la información en el marco jurídico interamericano, OEA/Ser.L/V/II. CIDH/RELE/INF, 1/09, 30 de diciembre de 2009.

Remiro Brontóns, A. y otros, Derecho internacional. Valencia, 2007.

Report of the Committee Set Up to Examine the Representation Alleging Non-Observance by Colombia of the Indigenous and Tribal Peoples Convention 1989 (n. ${ }^{\circ}$ 169), Made Under Article 24 of the ILO Constitution by the Central Unitary Workers' Union (CUT) and the Colombian Medical Trade Union Association (ILO), Doc. GB.282/14/3, noviembre 14 de 2001.

Stavenhagen, R., "Los pueblos indígenas y sus derechos", Informes Temáticos del Relator Especial sobre la situación de los Derechos Humanosy las Libertades Fundamentales de los Pueblos Indigenas del Consejo de Derechos Humanos de la Organización de las Naciones Unidas, Oficina de UNESCO en México.

U.N. GAOR, Report of the Committee on the Elimination of Racial Discrimination, , 50ª Sesión, Tema 103 de la agenda, párr. 536, U.N. Doc. A/50/18 (1995).

República Argentina, Juzgado de Primera Instancia n. ${ }^{\circ} 2$ en lo Civil, Comercial, Especial de Procesos Ejecutivos, Laboral y de Minería de la II Circunscripción Judicial con asiento en la ciudad de Cutral Có, "Petrolera Piedra del Águila SA c/ Curruhuinca Victorino y otros s/ acción de amparo", febrero de 2011, Considerando III consultado el 31 de enero de 2013, disponible en: http://www.mapuexpress. net $/$ ?act $=$ publications\&id $=4766$

República de Bolivia, Sentencia Constitucional 2003/2010-R, Sucre, 25 de octubre 2010, contra la Asamblea del Pueblo Guaraní Itika Guasu, 
Expediente: 2008-17547-36-RAC, Distrito: Tarija, Magistrado Relator: Dr. Marco Antonio Baldivieso Jinés.

República de Chile, Corte de Apelaciones de Concepción, Chile, 10 de agosto de 2010, consultado el 31 de enero de 2013, disponible en: http:/ / www.politicaspublicas.net/panel/jp/676-concepcion-rol289-2010. html

República de Colombia, Corte Constitucional, Sentencia T-428 de 1992 (24 de junio de 1992).

República de Colombia, Corte Constitucional, Sentencia SU-039 de 1997 (3 de febrero de 1997)

República de Colombia, Corte Constitucional, Sentencia C-891 de 2002 (22 de octubre de 2002)

República de Colombia, Corte Constitucional. Sentencia SU-383 de 2003 (13 de mayo de 2003).

República de Colombia, Corte Constitucional, Sentencia T-737 de 2005 (14 de julio de 2005).

República de Colombia, Corte Constitucional. Sentencias: T-880 de 2006 (26 de octubre de 2006).

República de Colombia, Corte Constitucional, Sentencia C-208 de 2007 (21 de marzo de 2007).

República de Colombia, Corte Constitucional, Sentencia C-030 de 2008 (23 de enero de 2008).

República de Colombia, Corte Constitucional, Sentencia, C-461 de 2008 (14 de mayo de 2008).

República de Colombia, Corte Constitucional. Sentencia T-154 de 2009 (12 de marzo de 2009).

República de Colombia, Corte Constitucional. Sentencia C-175 de 2009 de 18 de marzo de 2009.

República de Colombia, Corte Constitucional. Sentencia C-615 de 2009 (2 de septiembre de 2009).

República de Colombia, Corte Constitucional, Sentencia T-769 de 2009 (29 de octubre de 2009).

República de Colombia, Corte Constitucional, Sentencia C-063 de 2010 (4 de febrero de 2010).

República de Colombia, Corte Constitucional. Sentencia, C-702 de 2010 de 6 de septiembre de 2010

República de Colombia, Corte Constitucional, Sentencia, T-745 de 2010 (14 de septiembre de 2010). 
República de Colombia, Corte Constitucional, Sentencia T-129 de 2011 (3 de marzo de 2011).

República de Colombia, Corte Constitucional, Sentencia T-693 de 2011 (23 de septiembre de 2011).

República del Ecuador, Corte Constitucional, Quito, 18 de marzo de 2010, Sentencia n. ${ }^{\circ}$ 001-10-SIN-CC, Casos n. ${ }^{\circ}$ 0008-09-IN y 0011-09-IN (Acumulados).

República del Perú, Sentencia del Tribunal Constitucional, Exp. n. ${ }^{\circ} 0022-$ 2009-pi/tc, Lima, Gonzalo Tuanama Tuanama y más de 5.000 ciudadanos, 9 de junio de 2010, consultado el 31 de enero de 2013, disponible en: http://www.tc.gob.pe/jurisprudencia/2010/000222009-ai.html

Rodríguez, G. A., "El papel de la consulta previa en la pervivencia de los pueblos indígenas y demás grupos étnicos de Colombia”, en Instituto Latinoamericano de Servicios Legales Alternativos, "El derecho a la consulta previa en América Latina: del reconocimiento formal a la exigibilidad de los derechos de los pueblos indígenas", en El Otro Derecho n. ${ }^{\circ} 40$ (jun, 2009), consultado el 29 de abril de 2013, disponible en: http://ilsa.org.co:81/biblioteca/dwnlds/od/elotrdr040/ od40-gloria.pdf

Rodríguez, G. A., "La consulta previa en pueblos indígenas y comunidades afrodescendientes en Colombia", (2010), p. 78, consultado el 29 de abril de 2013, disponible en: http:/ / www.urosario.edu.co/urosario_ files/1f/1fd9b49f-b717-4dc1-8875-657612776cff.pdf

Ruiz Molleda, J. C., "La implementación del derecho a la consulta previa de los pueblos indígenas". Instituto de Defensa Legal, Lima, 2009.

Sala Constitucional de la Corte Suprema de Justicia de Costa Rica, Sentencia de Amparo 08019, Considerando V (8 sep. 2000), Expediente n. ${ }^{\circ}$ 00-000543-0007-CO.

Sala Constitucional de la Corte Suprema de Justicia de Costa Rica (8 de septiembre de 2000), Sentencia de Fondo, Recurso de amparo, Exp.: 00-000543-0007-CO, Redactor: Luis Fernando Solano.

Errico, S., "'The World Bank and Indigenous Peoples: the Operational Policy on Indigenous Peoples (O.P. 4.10). Between Indigenous Peoples’ Rights to Traditional lands and to Free, Prior and Informed Consent". International Journal on Minority and Group Rights 13: 367-390, 2006. 367.

The African Commission on Human and Peoples' Rights, Communication 276 / 2003, Centre for Minority Rights Development (Kenya) and 
Minority Rights Group International on behalf of Endorois Welfare Council v. Kenya.

United Nations, General Assembly, A/Hrc/17/31, 21 de marzo de 2011, Principio 3(c), consultado el 31 de enero de 2013, disponible en: http://www.ohchr.org/documents/issues/business/A.HRC.17.31. pdf

United Nations, Department of Economic and Social affairs, Division for Social Policy and Development, Secretariat of the Permanent Forum on Indigenous Issues, Taller técnico de las Naciones Unidas sobre el consentimiento libre, previo e informado de los pueblos indígenas, Nueva York, 17 - 19 de enero de 2005.

World Bank, "Annex 1. Operational Manual Statement 2.34: Tribal People in Bank-Financed Projects", febrero de 1982, adjunto al OPCS Working Paper Implementation of the World Bank's Indigenous Peoples Policy. A Learning Review (FY 2006-2008), agosto 2011.

World Bank, "Annex 2. Operational Directive 4.20. Indigenous peoples (1991)" adjunto al OPCS Working Paper Implementation of the World Bank's Indigenous Peoples Policy. A Learning Review, (FY 2006-2008), agosto 2011.

World Commission on Dams, Dams and Development, Report of the World Commission on Dams, noviembre de 2000.

Yrigoyen Fajardo, R., "De la tutela indígena a la libre determinación del desarrollo, la participación, la consulta y el consentimiento", consultado el 28 de abril de 2013, disponible en: http:/ ilsa.org.co:81/biblioteca/ dwnlds/od/elotrdr040/od40-raquel.pdf 
